\title{
LA ACTIVIDAD POLÍTICA DE FRANCISCO ANTONIO PINTO: 1823-1828. NOTAS PARA UNA REVISIÓN BIOGRÁFICA**
}

\begin{abstract}
Este artículo analiza la actividad pública de Francisco Antonio Pinto entre los años 1823-1828, poniendo especial énfasis en su participación intelectual e ideológica durante la fase final de las guerras de independencia y los comienzos de la construcción republicana de Chile. A través del estudio de su vida, se pretende dar una visión más o menos global de los distintos fenómenos socioculturales de esta época, como también un recuento de las ideas y proyectos políticos implementados por el régimen en cuestión. La participación de Pinto en los cargos públicos más importantes, complementada con su vocación intelectual, es un reflejo de la conformación de los gobiernos chilenos luego de la emancipación, y una prueba fehaciente de las estrategias que los políticos de entonces pusieron en práctica con el fin de instaurar un modelo republicano acorde con la realidad del país. En ese sentido, este artículo rescata la tesis de Julio Heise, en cuanto a considerar la década de 1820 como un cúmulo de años de formación y aprendizaje políticos antes que como un proceso "anárquico", tal como lo ha presentado la historiografía tradicional en repetidas ocasiones. El caso de la Constitución de 1828, que sirvió de base conceptual y jurídica para la Constitución de 1833, es un ejemplo de lo anterior.
\end{abstract}

Palabras clave: Constitución, federalismo, liberalismo, republicanismo.

This article analyzes the public activity of Francisco Antonio Pinto between the years 1823-1828, giving special emphasis to his intellectual and ideological participation during the last phase of the wars of independence and the beginning of the construction of the Chilean republic. Through the study of his life, we pretend to present a global vision of the different socio-cultural events of this period, and also an account of the ideas and political projects that this regime put in practice. Pinto's participation in many of the most important public offices, complemented with his intellectual vocation, is a reflection of the conformation of the Chilean governments after the emancipation, and a demonstration of the strategies that the politicians of that time implemented with the objective of establishing the best republican model to fit the reality of the country. In this sense, this article rescues Julio Heises's thesis, in which he challenges the traditional historiography and sees

\footnotetext{
Licenciado en Historia por la Pontificia Universidad Católica de Chile. Correo electrónico: juanluisossa@yahoo.com.

** Este artículo es un extracto del capítulo III de la Tesis de Licenciatura Francisco Antonio Pinto en los albores de la República, 1785-1828. Agradezco los comentarios y sugerencias del profesor Iván Jaksic.
} 
the decades of the 1820 's as years of political learning rather than as anarchic process. The case of the 1828 Constitution, which served as conceptual and juridical base for the 1833 Constitution, is an example of the above.

Key words: Constitution, federalism, liberalism, and republicanism.

El Antiguo Régimen ha muerto, para no volver jamás; pero ello no nos permite creer que, sobre sus ruinas, no se puede reconstruir más que el despotismo o la anarquía: ambos son los bastardos de la Revolución; solo la libertad es su hija legítima y quien, con ayuda de Dios, echará algún día a los intrusos.

ALEXIS DE TOCQUEVILLE

Este estudio analiza la vida de Francisco Antonio Pinto durante la década de 1820 , específicamente lo relacionado con su actividad pública durante los primeros gobiernos chilenos. La elección de ese periodo se debió a tres razones: por un lado, a que no existe ningún estudio biográfico que abarque detenidamente las distintas áreas de la vida de Pinto durante esos años, y menos su ideario político-intelectual, definido en la fase final del Antiguo Régimen y el comienzo de la república.

En segundo lugar, a que a través de su desempeño en diferentes cargos administrativos pueden observarse algunas de las tendencias ideológicas en boga luego de la independencia, como el federalismo y el liberalismo moderado, y de qué forma ellas intervinieron en su devenir como político. En este proceso participaron una gama importante de reconocidos actores históricos, como Ramón Freire, José Miguel Infante, Diego Portales y el propio Pinto, quienes, para bien o para mal, sentaron las bases de lo que sería la política nacional en los lustros venideros.

Finalmente, el artículo obedece a una razón historiográfica, cuyo objetivo es plantear la necesidad de revisar más detenidamente una década que, en muchos casos, ha sido considerada como una "anarquía". Siguiendo la propuesta metodológica de Julio Heise, intentaremos demostrar que este no fue un periodo anárquico sino uno de crisis y que, como tal, las proposiciones para superarlo fueron muchas, novedosas y serias. El resultado más evidente se logró en 1828, cuando la Constitución en que tuvo una gran participación José Joaquín de Mora vino a solidificar las bases de la institucionalidad de nuestro país.

Nacido en 1785, Pinto cursó sus primeros estudios en el Real Colegio Carolino, donde hizo amistad con muchos de los que encabezarían el movimiento de independencia. Posteriormente, obtuvo el título de abogado en la Real Universidad de San Felipe. En 1807, participó de las milicias agrupadas por el cabildo en los alrededores de Santiago con el fin de defender el territorio de un posible ataque inglés, cuya intención era crear una suerte de eje comercial entre el Río de la Plata -invadido a mediados del año anterior por William Beresford- con los principales puertos chilenos. Aunque esta amenaza no se concretó, los preparativos militares permitieron que se robusteciera la influencia de los cabildos americanos, y que los criollos comenzaran a exaltar sus fantasías en el arte de la guerra. 
Al enterarse de la invasión napoleónica a la península ibérica, los chilenos no dudaron en reiterar su lealtad al rey cautivo. Sin embargo, al ver que el Consejo de Regencia, en nombre de Fernando VII, se había arrogado unilateralmente la facultad de dirigir la política imperial española, los cabildantes dieron muestras claras de que las expectativas de los americanos habían aumentado demasiado en los últimos años como para que un organismo ajeno los manejara a su antojo. Al igual que los porteños, argumentaron que en ausencia del monarca el poder debía volver al pueblo, y que este debía ser el que eligiera la mejor forma de gobierno. Ello se concretó el 25 de mayo de 1810 en Buenos Aires, y el 18 de septiembre en Chile, cuando los dirigentes de ambos pueblos conformaron las primeras Juntas nacionales de su historia.

A partir de ese momento, la carrera política de Pinto se hizo cada vez más evidente. Luego de un fracaso comercial en el Perú, su participación en la emancipación fue progresiva y, por lo menos durante los siguientes diez años, internacional. Entre fines de 1811 y mediados de 1813, residió en Buenos Aires como agente del gobierno chileno, firmando el primer acuerdo diplomático entre ambos países y haciendo amistad con hombres de la talla de Bernardino Rivadavia. Luego, se le designó para viajar a Europa para conseguir que Roma, Francia e Inglaterra legitimaran la independencia chilena. Empero, las intenciones del gobierno no fueron tomadas en cuenta, y, a mediados de 1815, debió regresar al Río de la Plata con las manos vacías.

En Buenos Aires se enroló en la división del ejército porteño que se había establecido en Tucumán con el propósito de detener las fuerzas realistas provenientes del Alto Perú. Al poco tiempo, este contingente se puso bajo el mando de Manuel Belgrano, antiguo militar y diplomático, que había permanecido en Londres al mismo tiempo que Pinto. El chileno ganó rápidamente la confianza de Belgrano, y junto a él, luchó para que el ejército porteño no cayera en las manos de los caudillos regionales, que, para entonces, comenzaban a ganar preponderancia. Pero sus esfuerzos fueron en vano: después de más de tres años esperando en Tucumán a que el destino de la guerra los hiciera combatir, las diferencias regionales fueron más fuertes y obligaron a Belgrano y a sus hombres a replegarse en Buenos Aires. Pinto comprendió que sus actuaciones en el país vecino habían finalizado y que era momento de regresar a su patria después de casi diez años de ausencia.

Al poco tiempo de llegar a Chile, el entonces Director Supremo, Bernardo O’Higgins, le encomendó la misión de embarcarse hacia el Perú en una de las divisiones de la Expedición Libertadora. En suelo peruano, Pinto hizo amistad con José de San Martín y observó el momento en que el porteño fue designado Protector. También vio cómo los errores del Libertador le hicieron perder relevancia entre sus hombres, hasta el punto que ni siquiera sus buenas intenciones le sirvieron para sobreponerse a sus enemigos.

La caída de San Martín, en septiembre de 1822, produjo un claro distanciamiento entre las distintas nacionalidades que conformaban el Ejército en el Perú, cuestión que a Pinto le tocó vivir y sobrellevar en carne propia cuando se le nombró general en jefe de las fuerzas chilenas. Desde ese puesto criticó severamente el mal trato que recibían sus compatriotas de parte de los militares aliados, comunicándole a O’Higgins su impresión en repetidas ocasiones. A estos infortunios se unieron las derrotas sufridas por las tropas chilenas en Moquegua y Torata, 
a mediados de enero de 1823, además de las consecuencias de la abdicación de O’Higgins y su reemplazo por Ramón Freire.

Estas contrariedades llevaron a Pinto a pensar en la posibilidad de retirarse al norte de Chile, "donde esperaba reconcentrar sus fuerzas, procurarse los auxilios necesarios y ponerse en situación de volver a operar en el Perú bajo mejores condiciones"1. Y así lo hizo. Entre noviembre y diciembre de 1823, embarcó a sus hombres, primero con rumbo a Cobija y posteriormente al puerto de Coquimbo. A juzgar por las penurias de la división chilena, la decisión de Pinto fue acertada, aunque, por cierto, las críticas no demoraron en aparecer entre los políticos santiaguinos que miraban desde lejos la situación de sus compatriotas ${ }^{2}$. No obstante, ninguno de los militares que se encontraban en el lugar de los hechos cuestionó la maniobra. Incluso el propio Bolívar consideró que la estrategia había sido bien meditada, y cuando solicitó al gobierno de Freire que la división auxiliar de Chile volviera al Perú, pidió que fuese mandada "por sus mismos acreditados jefes" 3 . Pese a esto, aquella ayuda no se concretaría; no porque Pinto no lo deseara, sino porque los conflictos internos de Chile obligarían al gobierno de Freire a dedicar todos sus esfuerzos a derrotar a las tropas realistas que todavía operaban en la isla de Chiloé.

Como veremos a continuación, su regreso a Chile conllevó un vuelco profundo en su vida. Luego de más de trece años sirviendo como diplomático y militar a la causa de la revolución hispanoamericana, sus empeños comenzaban a enfocarse en la política interna de su país.

\section{Ministro DE GOBIERNo y RELACIONES EXTERIORES}

Días después de que la división chilena arribara a Coquimbo, Ramón Freire, en su calidad de Director Supremo, nombró a Pinto intendente de la provincia, con el objeto de que pudiera reorganizar a sus hombres de mejor forma y seguir "cooperando mas provechosamente á la guerra que se hace [...] contra el Exercito Español" en el Perú 4 . Con todo, antes de que Pinto comenzara esta nueva labor, el gobierno chileno suspendió los preparativos militares en Coquimbo, al verse obligado a organizar una expedición que desalojara el último bastión realista del territorio nacional. El grueso de ese ejército se conformó con los batallones 7 y 8 , establecidos en Coquimbo, con lo que la tropa al mando de Pinto comenzó paulatinamente a disminuir. A fines de febrero de 1824, la tropa había mermado considerablemente y la idea de volver al Perú ya no parecía un tema relevante.

\footnotetext{
1 Diego Barros Arana, Historia General de Chile, Editorial Universitaria y DIBAM, Santiago, 2001-2005, tomo XIV, 190-191. También véase Gonzalo Bulnes, Últimas campañas de la Independencia del Perú, Imprenta y Encuadernación Barcelona, Santiago, 1897, 302-308.

2 El Congreso resolvió, el 23 de diciembre de 1823, que "se escribiese por el Ejecutivo y el Congreso al libertador presidente de Colombia y al gobierno del Perú, haciéndoles una sincera manifestación de que ni el Congreso ni el gobierno de Chile habían tenido parte alguna en el regreso de las tropas", citado en Barros Arana [1], tomo XIV, 193. No obstante, aquel parecer mutaría con los futuros acontecimientos.

3 Citado en Bulnes [1], 308.

4 Archivo Nacional, Intendencia de Coquimbo, vol. 13, sin foja exacta. (De ahora en adelante citado como A.N.I.C.)
} 
Aún así, Pinto siguió cumpliendo sus funciones de intendente y de jefe castrense hasta junio de ese año. Durante estos meses, estuvo atento a las peripecias de sus compatriotas en el sur del país. El 9 de abril de 1824, recibió una carta de Mariano Egaña, a la sazón Ministro de Gobierno y Relaciones Exteriores, en que se le informaba que los patriotas habían tomado los fuertes de Chacao y Carelmapu y que se aprestaban a marchar hacia San Carlos de Ancud. Con esta noticia, Egaña pretendía hacer partícipes de aquellas victorias a los chilenos residentes en Coquimbo, pues de esa forma la unidad geográfica y política de la patria comenzaba a tomar cuerpo. Pero al mismo tiempo que el ministro escribía estas palabras, las fuerzas de la naturaleza, desencadenadas en Chiloé, obligaban a los patriotas a regresar al continente. El viento y las lluvias, como también la escasez de víveres y el rumor de que una división naval venía de España, impulsaron a los jefes de la expedición a abortar la empresa y dirigirse hacia Talcahuano con las manos vacías.

Los asuntos tampoco caminaban bien en la capital. La Constitución de 1823, cuya redacción se había encargado a Juan Egaña, no había dado los resultados esperados por la ciudadanía. En esas circunstancias llegaba Freire a Santiago, retomando el mando del país el 14 de junio de 1824, después de casi seis meses de ausencia. Su primer objetivo fue comentar al Senado el desastroso estado de la república, dejando entrever que era absolutamente indispensable concentrar todos los poderes del Estado en la dirección suprema y, desde él, proyectar una nueva Constitución.

La mayoría de los políticos santiaguinos apoyó la idea de Freire, señalando que las propuestas de Juan Egaña vulneraban la autonomía de las provincias y "en materia religiosa no respetaba la tolerancia"5. El estudio de su abrogación se vio favorecido con el alejamiento de Mariano Egaña del gobierno, quien había defendido con ahínco la obra de su padre y se había mostrado contrario a cualquier modificación en sus artículos ${ }^{6}$. En su reemplazo, Freire nombró el 12 de julio de 1824 a Francisco Antonio Pinto, a sabiendas que en su calidad de intendente de Coquimbo se había convertido en un crítico acérrimo de la Constitución de 1823 y que su preparación intelectual y jurídica ayudaría a aplacar al Senado y a las cada vez más duras ofensivas de los Egaña ${ }^{7}$.

5 Julio Heise, Años de formación y aprendizaje políticos 1810-1833, Santiago, Editorial Universitaria, $1978,156$.

6 Mariano Egaña se había dirigido a Londres en una misión diplomática. Como dice Simon Collier, Ideas y política de la independencia chilena, 1808-1833, Santiago, Editorial Andrés Bello, 1977, 265, "facilitó considerablemente la tarea de socavar la Constitución de 1823 la partida de Chile de Mariano Egaña, quien, en su calidad de Ministro del Interior, había estado haciendo denodados esfuerzos por implantar la nueva organización política en las provincias".

7 Este nombramiento se encuentra en Archivo Nacional, Ministerio del Interior A.N.M.I., vol. 61, f. 256 y dice lo siguiente: "A consulta de mi consejo de Estado y conforme ála constitucion, he venido en nombrar para Ministro Secretario de Estado en el Departamento de Gobierno y Relaciones Exteriores al Brigadier Don Francisco Antonio Pinto, de cuya providad y conocimientos me hallo satisfecho. El nombrado será puesto inmediatamente en posecion de este destino, para lo cual se le comunicará el presente decreto de que se tomará razon, y se inventará en el Boletin". (De ahora en adelante citado como A.N.M.I.) Es muy probable que Freire haya informado a Pinto de esta resolución algunos días antes, pues así podía dejar en buenas manos la intendencia de Coquimbo. Su renuncia a esta se verificó el 26 de junio de 1824, y en su reemplazo asumió José María Benavente. Véase A.N.I.C., vol. 17, f. 408. 
Junto a Pinto y a Diego José Benavente, Freire consiguió, el 19 de julio, que el Senado clausurara sus sesiones y que se le encargara exclusivamente "la administración del Estado por el término perentorio de tres meses" 8 . Aunque Freire fue el principal vencedor en la disputa con el Senado, fueron las ideas de Pinto las que estuvieron detrás de esta maniobra. Como intendente había presenciado la escasa aplicación de la Constitución en las provincias y, por consiguiente, se sentía con la autoridad moral e intelectual de objetarla en todos sus términos. Al igual que sus correligionarios políticos -que comenzaban a ser denominados liberales o pipiolos-, estuvo dispuesto a incrementar el poder del Director Supremo con tal de que una nueva Constitución fuera definitivamente aprobada. Es cierto que la clausura del Congreso podía ser mirada como una grave falta contra la democratización de la política nacional, pero más fuerte era la opinión de que la obra de Juan Egaña no respetaba los principios ideológicos de la independencia.

Esta idea no era una mera divagación intelectual. La mayoría de los chilenos, entre ellos Pinto y los Egaña, adherían al republicanismo, aunque muchas veces diferían en sus formas. Una de estas, y quizás la más relevante, hacía alusión al papel que debía tener la religión en un sistema representativo. Los grupos conservadores o pelucones -que en general habían mirado con buenos ojos la Carta de 1823- buscaban potenciar el poder del clero, sin importar que su prédica contrariara algunos de los postulados de la revolución. Los pipiolos, en cambio, pretendían disminuir lo más posible la influencia del catolicismo, aunque sin declararse abiertamente en contra de sus principios.

Para Freire y Pinto, a su vez, el poder civil debía ser igual o mayor que el de la Iglesia, ya que de ese modo nadie quedaba por sobre la ley y el tipo de régimen propiciado por el gobierno. Además, estimaban que la Iglesia se ligaba al despotismo español y que muchos de sus preceptos eran sinónimos del "oscurantismo" colonial. En este sentido, los sacerdotes que se habían mantenido leales a la Corona eran considerados peligrosos porque podían influir en las conciencias del pueblo chileno y, por ende, intervenir en ámbitos que el Estado consideraba de su competencia exclusiva.

Ese era el caso del obispo de la capital, José Santiago Rodríguez Zorrilla, quien, desde 1810, era un férreo opositor a la emancipación sudamericana y tenía gran ascendencia entre los pelucones. Aunque es efectivo que en 1824 su fidelidad al rey había disminuido considerablemente, no es menos cierto que seguía siendo un rival de temer para los pipiolos, hasta el punto que más de alguna autoridad había pensado privarlo de sus credenciales apostólicas. Esa oportunidad se presentó el 2 de agosto, cuando Pinto convenció a Freire de que Rodríguez Zorrilla era un peligro para el poder civil y dispuso en duros términos que se le despojara del mando de su diócesis. Dice:

La enorme responsabilidad que ha contraido el Director Supremo al encargarse dela administracion dela Republica, le ha constituido en la necesidad de sacrificar muchas veces sus mas gratas afecciones, siempre que lo ha demandado la conservacion del

$8 \quad$ Citado en ibidem, 282. 
orden establecido. Para ningun acto desu administracion ha tenido que hacer un exfuerzo mas extraordinario á su caracter, ni ha probado su corazon un sentimiento mas intimo que ahora que la justicia, la tranquilidad del pais, y el clamor de los habitantes del Estado reclaman imperiosamente la separacion de V.E.Y. dela administracion de esta Diocesis = Persuadido S.E. el Director Supremo de que la permanencia de V.E.Y. ála cabeza del Obispado compromete la tranquilidad del Pais y su seguridad, me previene diga á V.E.Y. de su orden como lo hago, que desde esta fecha queda V.E.Y. separado del mando de esta Diocesis?.

En otra comunicación, fechada el mismo 2 de agosto, Pinto decía que al obispo se le condenaba "por la constante oposicion que en todas las epocas dela revolucion ha manifestado ála Independencia Nacional" y por "la descarada proteccion que ha dispensado á aquellos Eclesiasticos que mas se han distinguido por su odiosidad á la revolucion, y notables servicios en favor de los Españoles"10. Es decir, a Rodríguez Zorrilla no se le castigaba por ser sacerdote, sino porque sus discursos contrarios a la emancipación podían influir negativamente en la ciudadanía.

Detrás de la expulsión del obispo de Santiago se encontraba la siempre incómoda discusión sobre el Patronato eclesíastico, es decir, sobre la relación entre el poder civil y la Iglesia. Esta había tomado nuevos aires con la llegada, en febrero de ese año, de la Misión Muzi, representada por el vicario apostólico, Monseñor Juan Muzi, su secretario Juan María Mastai, futuro Pío IX, y el abate José Sallusti. Para el delegado de Roma, la destitución del obispo no se ajustaba a derecho, toda vez que, "según lo mandado por el concilio tridentino"11, esa facultad correspondía solo al Papa. Es cierto que el Vaticano había concedido el Patronato a los reyes españoles durante la colonia, y que por tanto las Repúblicas americanas podían pretender heredarlo. Pese a esto, aquel derecho debía ser explícitamente cedido por el Papa, para lo cual se necesitaba en primer lugar que Roma reconociera y legitimara la independencia nacional.

Por otro lado, el conflicto ente el Estado y la Iglesia se agudizó cuando el gobierno, a través de Pinto, comenzó a secularizar algunas de las tradiciones y ritos católicos. Dos fueron los ámbitos intervenidos por el gobierno: las fiestas religiosas y las órdenes de regulares. En el primer caso, Pinto buscó reformular el contenido de las prédicas y reducir el número de festividades. El 2 de agosto, informaba que el presbítero Manuel Mata había predicado "con escandalo público" en la "Catedral una oracion funebre subversiva" y que el cura Juan Crisóstomo se hallaba "recluso en la Recoleta Dominica por aserrimo enemigo dela Independencia Nacional"12. El 7 de ese mes, en tanto, el ministro enviaba una epístola a Muzi, en que le decía que la reducción de las fiestas tenía "por objeto evitar los males que irroga ála sociedad la multitud de tales dias", ya que "tienen el privilegio de suspender la administracion de Justicia, y el Despacho de las oficinas publicas con

A.N.M.I., vol. 61, ff. 261v-262.

A.N.M.I., vol. 61, ff. 262v.

Citado en Barros Arana [1] tomo XIV, 291.

2 A.N.M.I., vol. 61, f. 263. 
grave perjuicio de los Ciudadanos"13. Al ver que el gobierno no cedería en esta materia, el vicario debió de mala gana disminuir las festividades anuales de diecisiete a doce ${ }^{14}$.

La reforma de los regulares, por su parte, generó también una fuerte discrepancia entre el poder civil y la Iglesia. En 1824, las órdenes religiosas se hallaban en una situación anómala, ya que después de la independencia habían sido separadas de las autoridades superiores que residían en Madrid o Roma, pero en la práctica seguían dependiendo de ellas ${ }^{15}$. Así, el ministro Pinto decidió someter a los regulares a los gobernadores diocesanos, quienes contaban con toda la confianza del Estado $^{16}$.

El 6 de septiembre se publicó un bando de quince artículos con el nuevo reglamento de regulares, cuyo trasfondo fue pensado y ejecutado por Pinto mismo. Comenzaba diciendo que "todos los regulares se recogerán á sus respectivos conventos á guardar vida comun, y la observancia de sus Constituciones", pero aquellos que quisieran exclaustrarse "ocurrirán al Gobernador de esta Diocesis para alcanzar su Secularizacion”. El artículo quinto impedía que el hábito de religioso fuese entregado a personas que tuvieran menos de veintiún años y el séptimo señalaba que "todo convento menor que de Prelado ó Lego tubiese menos de ocho individuos, se cerrará". El precepto número diez exoneraba a los regulares de la administración de los bienes eclesiásticos (los cuales pasaban a posesión del gobierno), para que de ese modo pudieran "exclusivamente consagrarse á su Ministerio" y no fueran "distraidos en atenciones profanas".

Días después, el Estado declaró que los sacerdotes que "por razón de su ministerio no estaban enrolados" en las filas de la independencia nacional, "no podían excusarse de defenderla por aquellos medios que les suministraba la influencia del altar". Esto iba acompañado de un decreto oficial, que reglamentaba el contenido de los sermones:

$1^{\circ}$. Los sacerdotes seculares ó Regulares en todas las oraciones que pronuncien en publico, bien sean panegiricos ó morales terminaran su discurso implorando los auxilios celestiales en favor dela conservacion dela Religion Catolica, dela concervacion y progresos dela independencia Nacional y Republica de Chile, del acierto desus magistrados y recomendando siempre álos pueblos la observancia y sumicion álas leyes patrias y autoridades encargadas de su execucion. $2^{\circ}$. Es tambien un deber de los Ministros del culto ilustrar álos pueblos sobre la necesidad, Justicia y utilidad de que Chile permanezca en Nacion Yndependiente de la España; hacerla conocer las ventajas desu independencia, demostrarles su utilidad y conveniencia; la deformar por si sus leyes arregladas álos principios que rigen á las sociedades mas $[i]$ cultas. En esta parte los Ministros

13 A.N.M.I., vol. 61, f. 266v.267.

14 Véase Barros Arana [1], tomo XIV, 293-294. El 9 de agosto se publicó la Reducción de fiestas. Indulto apostólico dirigido a los Sres. Ordinarios, Clérigos seculares y regulares, y a todos los fieles del Estado de Chile, firmado por Freire y Pinto, véase Lilliam Calm, El Chile de Pío IX: 1824, Editorial Andrés Bello, Santiago, 1987, nota al pie 41 de la 88.

15 Véase Barros Arana [1], tomo XIV, 291.

16 Véase A.N.M.I., vol. 61, ff. 274-274v. 
oradores escogerán el tiempo oportuno y contraeran en merito muy particular con el Gobierno los que se distingan en ellos ${ }^{17}$.

Es decir, la posición del gobierno no era abiertamente contraria al catolicismo (por algo se pedía por su conservación), sino partidaria de que sus ritos promovieran la independencia del país. Es claro también que el sistema republicano no era conocido por todos (en parte, porque las distancias entre las provincias y la capital impedían una buena comunicación), y que las prédicas de los párrocos podían ser una buena fuente de divulgación ideológica.

Los conflictos con el vicario apostólico pusieron fin a la visita de la Misión Muzi, pero no a la relación con Roma ${ }^{18}$. Al mismo tiempo que la discusión giraba en torno al derecho de Patronato, el dilema de la tolerancia religiosa comenzaba a asomar y a provocar las más serias repercusiones. Para los políticos chilenos, entre los que se encontraba Pinto, mantener una conexión diplomática con el Vaticano era de suma importancia, ya que de una u otra forma daba una legitimidad especial a la emancipación. Pero también era crucial contar con países que practicaban otros credos, como Inglaterra y Estados Unidos, pues en ellos residía el futuro de los intercambios comerciales.

El interés por generar un contacto internacional con las potencias europeas existía desde los primeros gobiernos nacionales. Recordemos que la Junta de 1813 había enviado a Pinto a Londres con el fin de conseguir el reconocimiento de la Corona británica, pero la negativa del gobierno inglés de aceptar cualquier movimiento revolucionario que afectara a los españoles había desmoronado toda negociación. Un poco más cercano era el vínculo con los norteamericanos, tanto en materias económicas como políticas. La apertura del comercio luego de las guerras de independencia permitió que algunos comerciantes anglosajones se establecieran en Valparaíso para seguir con sus propios ojos el destino de sus negocios, lo que, a todas luces, influyó para que Estados Unidos reconociera en 1822 la emancipación chilena $^{19}$. A partir de entonces, se produjo un intercambio cultural más o menos dinámico entre chilenos y norteamericanos. Sin embargo, esta relación también dio pie para que las formas de vida de los extranjeros chocaran con la tradición hispano-criolla de los chilenos, sobre todo en asuntos tan relevantes y sensibles como la religión.

A principios de 1824, llegaba a Santiago Heman Allen, ministro plenipotenciario estadounidense, con el propósito de generar contactos diplomáticos con Chile. Desde un comienzo, el agente recibió un trato amistoso por parte de las autoridades santiaguinas, las cuales veían en él la oportunidad de informar al mundo los objetivos de la independencia nacional. Allen pensaba que la libertad y el respeto a la ley eran los únicos garantes del progreso de cualquier país. Si así no fuera, el desorden y la corrupción administrativa podían tomarse los pasillos gubernamenta-

17 A.N.M.I., vol. 61, ff. 285-285v.

18 Véase Barros Arana [1], tomo XIV, 295-297.

19 Portugal había reconocido la independencia chilena en 1821. Véase idem. 
les y llevar a un colapso político que podía hacer tambalear todo el sentido de la revolución ${ }^{20}$.

De una u otra forma, el gobierno de Freire adhería a los principios ideológicos del estadounidense. No obstante, a mediados de ese año, y al mismo tiempo que Pinto se enfrentaba a Muzi por el destierro de Rodríguez Zorrilla, un pequeño conflicto en torno a la tolerancia vino a poner en jaque la relación. En los pocos meses que llevaba en Chile, Allen había podido crearse una opinión certera sobre el trato que recibían sus compatriotas, tanto en materias comerciales como religiosas. En cuanto a las primeras, el ministro plenipotenciario no tenía mayores quejas, comprendiendo que el tiempo se encargaría de dinamizar y formalizar los negocios entre ambas naciones. Las segundas, en cambio, le preocupaban seriamente, en especial lo referente a las exequias de sus compatriotas que fallecían en Chile. El 24 de agosto escribía a Pinto para manifestarle su preocupación por la cuestión de los cementerios:

El Ministro Plenipotenciario de los Estados Unidos tiene el honor de representar al Señor Ministro de Relaciones Exteriores [Pinto] que observa con mucho dolor que por las leyes y costumbres de Chile, sus compatriotas, como otros extranjeros, se hallan privados del libre ejercicio de su acostumbrado culto, y los solemnes ritos del entierro; que ha sabido que en algunas ocasiones se han cometido vergonzosas indecencias con los cuerpos difuntos de sus compatriotas; y que por lo tanto se halla forzado él mismo, por la obligación y cumplimiento de su deber, en cuanto representa a los ciudadanos de los Estados Unidos, a llamar respetuosamente la atención del gobierno de Chile sobre la necesidad de proveer con alguna ley a la protección de esos privilegios que están acostumbrados a gozar; bien entendido que esto debe entenderse con los actuales residentes, y aquéllos que vengan o sean transeúntes ${ }^{21}$.

A juzgar por la carta de Allen, el cementerio de disidentes construido por O’Higgins en Valparaíso no había garantizado que los ritos funerarios de los estadounidenses se cumplieran. Para los protestantes significaba un duro revés que sus muertos fueran enterrados con la ceremonia inadecuada, como también que los católicos más sectarios ultrajaran los cuerpos. Esto no significaba que la Iglesia apoyara explícitamente este tipo de aberraciones, pero, al no detenerlas, demostraba su afán de luchar hasta las últimas consecuencias con tal de mantener su influencia entre los chilenos.

Cuatro días después del comunicado de Allen, el gobierno chileno contestó. En la ocasión, Pinto fue quien firmó la carta, mostrándose bastante comprensivo con las peticiones del norteamericano. Como otras veces, Pinto aprovechó la ocasión para recalcar las diferencias entre el republicanismo y el mundo colonial, arguyendo que la aceptación del culto protestante solo era posible en un sistema político donde se respetaran la libertad y las diferencias entre sus habitantes. Además, con un lenguaje bastante adelantado para su época, se refería a términos

20 Véase Barros Arana [1], tomo XIV, 262-263.

21 Citado en Ricardo Donoso, Las ideas políticas en Chile, Fondo de Cultura Económica, México, 1946, 240-241. 
como "civilización” y "progreso" y dejaba entrever que el Director Supremo estaba dispuesto a satisfacer cada una de las necesidades de los estadounidenses residentes en el país:

El Ministro que suscribe [Pinto] tiene el honor de haber recibido la apreciable nota del señor Ministro Plenipotenciario de los Estados Unidos de 24 del presente, relativa a que se permita a los ciudadanos de aquella república el ejercicio de su culto y la celebración de sus ritos funerales para que puedan sepultarse sus cadáveres con el respeto y decencia que pide la religión y demanda la civilización del siglo. El que suscribe está persuadido de la justicia de esta reclamación y la encuentra no solamente conforme a los respetables intereses de la buena moral y costumbres, sino que la cree de la más próspera trascendencia al bien y progresos de esta república. Las reliquias de la educación colonial recibida de manos de la nación menos culta de Europa [España], no habían aún permitido a los nuevos gobiernos cimentar sus instituciones en la parte religiosa, como lo exigía la civilización y sus propios intereses, y ha sido forzoso marchar con alguna lentitud a fin de que los mismos pueblos se hagan capaces de recibirlas y adoptarlas. El Director Supremo de la República [sic], persuadido de la importancia de una ley que proteja a los extranjeros en el goce de estos privilegios, que no pueden negarseles en el país alguno culto, trabaja por establecerla prontamente, y aplaudiendo los sentimientos filantrópicos del señor Ministro Plenipotenciario de Estados Unidos, me ordena exprese al señor Ministro que tendrá la complacencia S.E. el Director de proporcionar a los ciudadanos de Estados Unidos estas garantías para una tranquila mansión en esta república ${ }^{22}$.

De más está decir que la voluntad de Pinto no fue suficiente para detener un conflicto que duró prácticamente todo el siglo XIX, y que por ende, esta parecía una declaración de principios antes que una promesa apta para satisfacer las expectativas de Allen. Sin embargo, es bastante relevante que la discusión sobre el respeto a la diversidad comenzara a tomar fuerza en un periodo tan temprano, pues significa una maduración evidente en los intelectuales y políticos chilenos. Incluso la prensa adicta al gobierno quiso intervenir en el debate: El Liberal, por ejemplo, señaló que la religión católica debía mostrar una cara más tolerante si pretendía sobrevivir y que "la ignorancia y el fanatismo en que el país se halla sumido" podía afectar futuras negociaciones diplomáticas con Estados Unidos ${ }^{23}$.

Así, pues, avenir lo religioso con lo político, y extender todo ello a los planos económicos y culturales parecía la consigna del gobierno, para la cual estaba dispuesto a operar en cualquier esfera pública. Incluso no dudó en utilizar la intervención electoral con el objetivo de que el nuevo Congreso fuera afín a las propuestas del gobierno. Desde septiembre de 1824, se llamó a elecciones de diputados, y se encargó a los intendentes provinciales que escogieran a los candidatos más adeptos al régimen. Así, por ejemplo, el 20 de octubre Pinto agradecía al intendente de Coquimbo que hubiera cumplido acertadamente esta tarea:

22 Citado en ibidem, 241.

23 Citado en ibidem, 242. 
Queda instruido el Supremo Director dela acertada eleccion de Diputados que ha hecho esa Intendencia para el proximo Congreso general. Delas virtudes civicas, honor, y patriotismo de los electos, espera la Patria los mas felices resultados en el gran negocio de que van á ocuparse, pues que de sus luces, y providad, pende la futura suerte de la Nacion $^{24}$.

El nuevo Congreso abrió sus sesiones el 22 de noviembre de 1824, en cuya ocasión el Director Supremo dispuso que se hiciera "una salva en la fortaleza de Santa Lucia, y se repiquen generalmente las campanas por espacio de una hora en todas las Yglesias dela Ciudad" 25 . Los miembros del antiguo Senado conservador, cerrado por Freire unos meses antes, movidos por Juan Egaña, intentaron hacer un último esfuerzo para que la Constitución de 1823 subsistiera. No obstante, a instancias de Pinto $^{26}$ y de Benavente, el gobierno logró derogar la Constitución por completo y, el 4 de enero de 1825, se comenzaron a planificar las leyes que regirían al país hasta que se publicara un nuevo código fundamental. De ahí en adelante, comenzó una larga y difícil tarea por afianzar legalmente el sistema republicano, en la que chocarían las más diversas tendencias y aspiraciones de los miembros del Congreso.

La labor de Pinto como ministro del interior concluyó poco después. Durante estos meses, había vivido la complejidad de la política y se había enfrentado a un cúmulo de personas que, por distintas razones, pensaban de otra manera. Con él, se inauguró una forma de hacer política cuyo fin era difundir el republicanismo por todo el país y conseguir que los nuevos ciudadanos adhirieran paulatinamente a los beneficios de la independencia. Pero también era consciente de que él no era la persona adecuada para estar en la primera línea del debate, más aún luego que los ataques a su persona se incrementaran durante los últimos meses ${ }^{27}$. Por ello, el 22 de febrero de 1825 presentó su renuncia al ministerio, acusando "quebrantos" en su salud. Freire aceptó su dimisión y le agradeció explícitamente los interesantes servicios que había prestado a la Nación ${ }^{28}$.

\section{LA INTENDENCIA DE COQUIMBo}

A principios de 1825, el Congreso Nacional había alcanzado muy pocos de los objetivos que se había impuesto el día de su apertura. El gobierno de Freire miraba con asombro cuanto ocurría alrededor, haciendo lo posible por mantener el orden y el respeto a la ley, aunque no siempre con éxito. En buena medida por ello el

24 A.N.I.C., vol. 13, sin foja exacta.

25 A.N.M.I., vol. 61, f. 320.

26 La defensa de Pinto se titula Memoria del ministro del interior en contestación al mensaje del senado y está reproducido en ibidem, vol. 10, número 151.

27 En su Memoria, Juan Egaña se refirió a Pinto con las siguientes palabras: "El Ministro Pinto sería el más ilustre facineroso si a las disposiciones del corazón le acompañasen las prendas y talentos del genio; su inconsideración y falta de decoro es inminente", citado en Barros Arana [1], tomo XIV, nota al pie, 278.

28 Véase A.N.M.I., vol. 61, f. 354. 
Director Supremo interrumpió el retiro de Pinto y apeló nuevamente a sus condiciones políticas, para aminorar el descalabro administrativo. Esta vez se le encomendó la Intendencia de Coquimbo, uno de los cargos más trabajosos de la época ${ }^{29}$.

Pinto asumió el 5 de abril de $1825^{30}$, casi al mismo tiempo que Coquimbo desconocía la autoridad del Congreso. Al igual que Concepción, los coquimbanos retiraron de Santiago a sus diputados, por considerar que el Poder Legislativo no poseía legitimidad suficiente. El 22 de mayo, los vecinos de Coquimbo convocaron una Asamblea provincial, argumentando "que era innerente á esta Ciudad, como Capital de la provincia, la facultad de invitar a sus partidos" 31 . Es muy probable -a juzgar por su conducta posterior- que Pinto estimara que esa Asamblea podía ser una buena instancia para abrir una comunicación más fluida con el gobierno. Coincidentemente, el 26 de ese mes Freire dio una clara señal en favor de las provincias, cuando llamó al vecindario de Santiago a elegir su propia Asamblea. Su objetivo sería "reunir la voluntad general de la provincia en el nombramiento de dos plenipotenciarios", quienes, "en consorcio de los nombrados por las asambleas de Concepción y Coquimbo" establecerían "la ley de elecciones para una legislatura central" 32 .

Pese a esto, las diferencias entre algunos políticos de la capital y las provincias resurgieron el 13 de junio, fecha en que la oposición a Freire aprobó la creación de una Junta de gobierno, compuesta por José Miguel Infante, Carlos Rodríguez y José Antonio Ovalle. Su objeto era reducir las facultades del Director Supremo, obligándolo a compartir el Poder Ejecutivo con la Junta. Los coquimbanos resintieron que la autoridad del Director Supremo se debilitara y que los juntistas impusieran "su voluntad y sus caprichos a la República entera" 33 , por lo que se inclinaron más a Freire que a la Junta.

En Coquimbo, los preparativos para la apertura de la Asamblea provincial estuvieron a cargo del mismo Pinto, quien, en un comunicado al ministro del interior, informó de todas las ceremonias y festividades que la acompañarían ${ }^{34}$. En carta al gobierno, señalaba que la instalación de este cuerpo le "proporcionaba un placer puro", pues permitía que el pueblo expresara "libremente su voluntad por el organo de los individuos que le han merecido su confianza, escribir sus leyes, poner las bases de su propiedad, y fixar para siempre sus destinos"35. La explícita adhesión a la Asamblea por parte de Pinto se debía al respeto que los coquimbanos profesaban a Freire ya los representantes del gobierno, entre los cuales él era el más importante de la provincia. Por eso, estar presente el día de la apertura era un deber que le cabía en su calidad de intendente, como también lo era presenciar el juramento de los integrantes, cuyo texto decía lo siguiente:

\footnotetext{
29 El nombramiento es del 23 de marzo de 1825, véase A.N.I.C., vol. 14, sin foja exacta.

30 Véase A.N.I.C., vol. 17, f. 479.

31 A.N.I.C., vol. 17, f. 482.

Citado Barros Arana [1], tomo XIV, 382.

Ibidem, 385.

Véase A.N.I.C., vol. 10, ff. 51-52v.

Ibidem, f. 51.
} 
Representantes de la Provincia de Coquimbo: jurais por Dios y estos Santos evangélios mantener la libertad, independencia, integridad del Estado, y de la provincia: no omitir medios para libertarla de sus opresores: desempeñar fiel y legalmente los poderes que os han confiado los pueblos, y llenar los altos fines para que habeis sido convocados y guardar secreto en las materias que se tratasen en sesiones de este género ${ }^{36}$.

Es interesante el trasfondo de este juramento. Por un lado, reafirmaba que los coquimbanos pertenecían al Estado de Chile y que mantendrían la integridad de la república. Pero, además, tenía un aire regionalista, recordando que los miembros de la Asamblea también debían velar por la integridad de la provincia. Como Pinto fue quien comunicó favorablemente al gobierno lo que sucedía en Coquimbo, es evidente que aquel se sentía a gusto con la creación de la Asamblea y que sus miembros podían gozar de su apoyo. Esto se confirmó el 26 de junio, cuando la Asamblea votó que Pinto la representara ante cualquier cuerpo legislativo que en el futuro se instaurara en Santiago ${ }^{37}$.

Ese mismo día, Pinto se presentó ante los asambleístas para manifestar su impresión sobre los últimos acontecimientos. En un extenso e interesante documento, propuso ciertas modificaciones educacionales, económicas y políticas en beneficio de la provincia. Pinto pensaba que la primera preocupación de la Asamblea debía ser la búsqueda de soluciones para que la educación en Coquimbo tomara el camino correcto. Como hijo de su tiempo, creía que una buena instrucción pública garantizaba la "inmortalidad" de la libertad y la consolidación de la "civilización" de los pueblos. En este proyecto, solo el trabajo mancomunado entre el centro -el gobierno- y la periferia -la Asamblea- permitiría que las escuelas primarias, "bace de la educacion", se difundieran en todo el territorio.

En los pocos meses que llevaba como Intendente, Pinto había conocido bien la cantidad y la calidad de los establecimientos educacionales. Su investigación le había suministrado los siguientes datos:

El Colegio de esta Ciudad [La Serena] es la unica casa de estudios que tiene la Provincia y con las mejoras de que es suceptible es muy suficiente para la educacion literaria de su juventud. Su ereccion es devida á la filantropia de unos cuantos Ciudadanos á quienes la Provincia deve este precioso Taller de su prosperidad futura. El se conserva en un pie regular por el infatigable empeño de su [h]abil Director, y apreciable cooperacion de su Catedraticos en esta honorifica empresa: mas sus esfuerzos son insuficientes para colocarle en el grado de elevacion y provecho que ellos desean y que imperiosamente demandan los intereses de la Provincia. La falta de libros elementales y de algunas maquinas son obstaculos poderosos para difundir la enseñanza. El mejoramiento de su local, un buen reglamento interior y la dotacion de algunas otras Catedras, sin cuyas ciencias ni puede pararse el hombre en nuestro actual estado de sociedad, ni arribar los pueblos al gose de las ventajas sociales, darian á este establecimiento un impulso saludable y capaz de corresponder dignamente al grande encargo que tenemos que legar a nuestra posteridad ${ }^{38}$.

\footnotetext{
36 Ibidem, f. 52.

37 Véase A.N.I.C., vol. 10, ff. 53-53v.

38 Ibidem, ff. 486-487.
} 
Su alocución prosiguió con un pormenorizado análisis de la realidad económica de la región y de su potencial. Según él, la "industria" de Coquimbo podía explotarse mucho más, en especial si se abrían las puertas a las inversiones extranjeras y se protegía la propiedad privada. Durante siglos, los "Mostruosos reglamentos de Comercio", habían impedido el intercambio fuera del imperio español, hasta el punto de mantener "estacionaria" prácticamente toda la actividad comercial. Ahora, en cambio, los chilenos tenían la posibilidad de vincularse económicamente con otras naciones.

Además de abrirse al comercio internacional, los coquimbanos debían explotar sus riquezas naturales, y así generar un intercambio entre los distintos pueblos que conformaban la provincia. Pinto creía que en una economía incipiente como la coquimbana, donde la agricultura y la minería eran los dos grandes focos de producción, el Estado debía hacer cumplir las leyes comerciales y fomentar la modernización de los mecanismos de explotación, pero jamás coartar la iniciativa privada. A propósito de la inversión foránea en la minería, pero también extensible a la producción en general, Pinto sostenía que la actividad extractiva ofrecía grandes perspectivas, en el entendido que a sus empresarios se les brindara "el goce de livertad en su giro, igualdad en las franquicias e inviolavilidad en sus personas y propiedades"39.

Por otro lado, los integrantes de la Asamblea de Coquimbo necesitaban oír que el gobierno central se preocupaba por su bienestar, como también sentirse parte de la magna empresa de difundir el republicanismo. Por ello, Pinto concluyó su Mensaje ante la Asamblea pidiendo a sus miembros que se integraran al proyecto del gobierno:

Aunque la representasion nacional no exista de hecho por circunstancias que os son notorias, el loable celo del Supremo Director por la concervasion de los derechos del pueblo Chileno no há podido tolerar una larga acefalia legislativa, y os pide dos Diputados para que en union de los que nombren las otras Asambleas constituyan la legislatura nacional: y es siertamente mas peligroso que la autoridad soberana tenga que mendigar sus atribuciones de las Asambleas provinciales, que el que estas resiban, las que le son peculiares de este centro nacional; pero solamente de ese modo las deliberaciones de ambas podrian girar en orbitas perfectamente concentricas ala felicidad de los Chilenos ${ }^{40}$.

El 1 de julio de 1825 la Asamblea de Coquimbo aprobó una "Ley Fundamental". El primer artículo señalaba que "la Provincia de Coquimbo es una parte integrante y esencial de la Republica de Chile" y que, por tanto, se sometería y cumpliría "las leyes generales que emanen dela representacion nacional". A la espera de que esta se reuniera, decía el artículo quinto, la Asamblea "reconoce el Executivo general depositado en la persona del Señor Don Ramon Freyre como Director Supremo". A continuación, declaraba que los coquimbanos se reservaban "la facultad de revisar la Constitucion politica dela Nacion y aquellas leyes que

39 Ibidem, ff. 488-488v.

40 Ibidem, ff. $489 \mathrm{v}-490$. 
tengan el caracter de fundamentales: para ratificarla, ó no sino lo estimase conveniente". Sin embargo, si una de las leyes aludidas en el artículo anterior "no tuviese la aprobacion de esta Asamblea, obtendrá en la Provincia Su Valor y cumplimiento, si pasasse en las otras dos [Santiago y Concepción]"41. Así, los coquimbanos se allanaban a participar en la elección del próximo Congreso, tal como el Director Supremo se los había solicitado un mes antes. En ningún caso, la Asamblea buscaba la autonomía de la provincia; por el contrario, al ver que Freire estaba dispuesto a oír la voz de Coquimbo, se sentía a gusto con la administración central y quería formar con ella un gobierno nacional.

A pesar de esto, antes de que las buenas intenciones del gobierno llegasen a concretarse, los intereses personales abortarían las negociaciones entre la provincia y la capital. En un acto inesperado y de difícil comprensión, el 12 de julio Freire llamó a los habitantes del país a elegir un nuevo Congreso Nacional, que entraría en funciones el 5 de septiembre de 1825 , olvidando que los plenipotenciarios de las tres provincias debían ser los que -previamente- acordaran la "ley de elecciones para una legislatura central". La resolución de Freire se hizo para complacer a la Junta gubernativa de Santiago encabezada por Infante, que, desde hacía algunos días, estaba haciendo denodados esfuerzos por formar un nuevo Poder Legislativo. Su intención era seguir debilitando la influencia de la dirección suprema, sin importar que las promesas incumplidas pudieran afectar la relación entre la capital y las provincias.

El 28 de julio, los coquimbanos manifestaron al ministro del interior su descontento por la forma en que se había llamado a elecciones para un nuevo Poder Legislativo. Insistían que ese Congreso era "prematuro", "estemporaneo i contrario a nuestros intereses". A raíz de estos acontecimientos, Pinto se encontró en una ardua disyuntiva. Como funcionario del gobierno, debía comunicar a los asambleístas sus resoluciones y hacer que ellas se cumplieran sin mayor dilación. Pero, en su fuero interno, es muy probable que se sintiera pasado a llevar e incluso molesto con la decisión de Freire. Recordemos que en el Mensaje de apertura de la Asamblea había pedido que se eligieran cuanto antes los dos plenipotenciarios, señalando que esa era la única garantía de que la provincia tuviera una participación activa en la representación nacional. Ahora, en cambio, al desconocerse aquel acuerdo, la inmensa credibilidad alcanzada por el intendente estaba en juego, y más de alguien podía pensar que a Pinto también le cabía responsabilidad en la decisión que unilateralmente se había tomado en la capital.

Con todo, los miembros de la Asamblea no formularon ningún cargo al intendente. Quizás esto se debiera a que Pinto consideraba que los cuestionamientos de la Asamblea no eran exagerados, como también a su casi segura participación -anónima, por cierto- en la redacción de las epístolas que esta enviaba a Santiago justificando su postura. Esta presunción nace cuando se lee la respuesta expedida por la Asamblea el 9 de agosto, cuando recibió la carta de la Junta de gobierno en que se le invitaba a participar del futuro Congreso. La forma en que

41 A.N.I.C., vol. 17, f. 493. 
se plantean los argumentos de la respuesta recuerda la posición que, desde un principio, había tenido Pinto frente al tema. Echando mano a los principios igualitarios de la revolución, la Asamblea recordaba que Coquimbo tenía los mismos derechos y deberes que Santiago. Por ello, la capital no podía arrogarse la facultad de cambiar por sí sola las reglas del juego:

Aunque conocemos la urgente necesidad de formar un Congreso, que dicte las Leyes generales que han de servir de norma á nuestras operaciones, es preciso, que las preceda un cuerpo orgánico [los plenipotenciarios] constituido por las respectivas Asambleas de las diferentes Provincias: que forme la sábia ley de elecciones; que señale los límites de las atribuciones reciprocas, y que celebre entre partes iguales este pacto tan suspirado. El siglo diez y nueve que ha preparado tan notables variaciones en las opiniones humanas, y por consiguiente una revolucion, nos impone la obligacion de figurar en el mundo civilizado, como una nacion respetable; mas bien que como una orda de bárbaros sin leyes y sin costumbres. ¡Qué la mas dulce armonía vuelva á formar los nudos del resorte poderoso, que nos reunió despues de los heróycos esfuerzos que coronaron nuestra Independencia, y que el cuerpo augusto que nos ha de dictar leyes, principie su obra con esa integridad, y sabiduría, que hacen madurar los acontecimientos sin precipitarlos! ${ }^{42}$.

Los coquimbanos concordaban con la Junta y con el Director Supremo en que la nación necesitaba un Congreso Nacional, por lo que era errado y prematuro suponer que los asambleístas tenían aspiraciones federalistas. Esto no quita que desearan ser tratados de la misma forma que los santiaguinos y los penquistas, sobre todo si había sido el mismo Freire quien había ideado la fórmula de negociación entre los plenipotenciarios. Es decir, aceptaban explícitamente el llamado que Pinto les hiciera en la apertura de la Asamblea, manteniendo intacta su resolución de no formar un Congreso hasta que las tratativas fueran en verdad trilaterales ${ }^{43}$.

Las negociaciones se entramparon definitivamente el 13 de agosto, fecha en que el ministro del interior contestó la carta que la Asamblea le enviara el 28 de julio, señalando que una "reunion de una Junta de Plenipotenciarios de las provincias" atrasaría "el restablecimiento de la unidad nacional i gubernativa", pues perfectamente podía suceder que "los Plenipotenciarios de Santiago no fuesen de acuerdo con los de Concepcion i Coquimbo sobre el modo de convocar un nuevo Congreso" 44 . Así, por última vez instaba a los coquimbanos a sumarse a la iniciati-

42 Oficio de la Asamblea de Coquimbo contestando al de la Junta, La Serena, 9 de Agosto de 1825, ff. 51-52.

43 En este caso, estamos en desacuerdo con el historiador inglés Simon Collier [9] quien afirma que Coquimbo tenía pretensiones federalistas en una fecha tan temprana como julio de 1825 . Es cierto, como lo expone Collier, que los coquimbanos escribieron a Freire el 10 de ese mes una sentida carta en que decían: "preferimos cualquiera estado de existencia política a la ignominiosa degradación de vernos esclavos del insano capricho de ese odioso nombre de capital". Mas, ¿a quién se refieren? ¿A Freire, a todos los santiaguinos o a la Junta de gobierno encabezada por Infante? A nuestro entender, hacen alusión a esta última, ya que fueron sus miembros los que no cumplieron con el acuerdo establecido en mayo de 1825 , en cuanto a que fueran los plenipotenciarios de las tres provincias los que decidieran la mejor ley de elecciones para el Congreso Nacional.

44 SCL, vol. 10, 323. 
va del Ejecutivo; de otro modo la provincia se quedaría sin representación en el Poder Legislativo.

Y así ocurrió. Durante el mes de agosto, se llevaron a cabo las elecciones de diputados al Congreso Nacional en los pueblos que conformaban la provincia de Santiago y, el 15 de septiembre, se inauguraron sus sesiones.

No obstante, con el paso del tiempo la discusión referente al nuevo Congreso disminuyó sustancialmente. En el caso de Coquimbo, los asambleístas se marginaron casi por completo del debate nacional, cuando se supo que un rico mineral de plata había sido descubierto en la localidad de Arqueros. El hallazgo se hizo por casualidad en agosto de 1825 , y rápidamente apartó a los coquimbanos de sus inquietudes políticas.

La mejor fuente para conocer la historia de los inicios de este mineral es el diario de viaje en Chile del francés Gabriel Lafond de Lurcy, a quien tocó estar presente en la región en los días en que se difundió la noticia. En esta época, los intendentes eran los funcionarios públicos a quienes competía la responsabilidad legal de otorgar las pertenencias mineras a los interesados, por lo que a Pinto cupo un papel de primera importancia. Cuenta el viajero francés que la primera pertenencia fue solicitada por el comerciante Ramón Subercaseaux. Ese mismo día, Mariano Ariztía, amigo de Pinto y en cuya casa se encontraba alojado, habría sugerido a este que se integrara al negocio. Luego de pensarlo, el intendente le habría contestado: “¿Cómo quieres que me convierta en minero?; no tengo ninguno de los conocimientos necesarios para esto y además carezco de dinero. Sin embargo, si quieres, Ariztía, pedir la estaca, lo que tal vez será conveniente, ya que soy aquí el soberano juez de los derechos de todos, quiero asociarme contigo. Subercaseaux me prestará \$3.000, tú pondrás igual cantidad y tentaremos el negocio". Ariztía aceptó, y solicitó una estaca a la derecha de la de Subercaseaux ${ }^{45}$.

Con todo, ¿podían ser los intendentes juez y parte en un pedimento minero? ¿Qué decía la legislación de la época? En ese entonces, seguían vigentes las Ordenanzas de Nueva España, dictadas por Carlos III en 1783, y que en diecinueve títulos señalaban las normas que se debían seguir en el ramo de la minería. El artículo tres del título séptimo preceptuaba que: "No podrán tener minas los Gobernadores, Intendentes, Correjidores, Alcaldes mayores, ni otros cualesquiera justicias de los reales ó asientos de minas, ni ménos los Escribanos de ellos; pero les concedo el que puedan tenerlas en distinto territorio del de su jurisdiccion" 46 . Es decir, a Pinto le estaba vedado acceder a una pertenencia ubicada dentro de su

45 Gabriel Lafond de Lurcy, Viaje a Chile, Editorial Universitaria, Santiago 1970, 104-106. Cabe señalar que el francés escribió estas páginas en 1853, y que, por lo tanto, muchos de sus datos pueden haberse oscurecido por el paso de los años. Aún así, al ser la única fuente primaria que describe los primeros tiempos de Arqueros, se nos hace imposible obviarla. También puede verse Benjamín Vicuña Mackenna, El Libro de la Plata, Editorial Francisco de Aguirre, Buenos Aires, 1978, 73-77.

46 Reales Ordenanzas para la direccion y rejimen y gobierno del importante cuerpo de la Mineria de Nueva-España y de su Real Tribunal Jeneral de orden de su Majestad, reimpresa en Santiago de Chile: Imprenta de la Opinion, por R. Rengifo, año de 1833, 37. Es muy probable que esta reimpresión se haya hecho para esclarecer las dudas surgidas por la constante explotación minera en el norte del país. 
jurisdicción, toda vez que su cargo de intendente, cuya naturaleza era semejante a la que le daban los españoles en el siglo XVIII, se lo impedía por completo. Más aún, en un documento firmado por Pinto el 16 de septiembre, la intendencia reconocía la autoridad de las Ordenanzas e incluso llamaba a obedecerlas ${ }^{47}$.

Por ello, la actuación de Pinto en la cuestión de Arqueros, cuyos detalles completos no hemos podido aclarar, es a lo menos equívoca. No era apropiado que hiciera uso de su calidad de intendente frente a Ariztía, e incluso animarlo a pedir la pertenencia. Por otra parte, surge la impresión de que Pinto se transformaría, de hecho, en un socio oculto de la pertenencia, o más bien de que en la propiedad de esta última tendría una cuota. Aunque ambas hipótesis podrían llegar a calificarse como legales de acuerdo con el tenor estricto de las Ordenanzas, no parecen serlo desde un punto de vista rigurosamente ético ${ }^{48}$.

En cualquier caso, la participación de Pinto en Arqueros no parece haber suscitado suspicacias. Por el contrario, los habitantes de Coquimbo y la Asamblea provincial aceptaron que Pinto actuara como juez en las disputas mineras ${ }^{49}$. Para los coquimbanos era más relevante contar con un intendente que mostrara interés y preocupación por la materia, que los aspectos jurídico-morales que pudieran empañar su actuación. Así, pues, recordando que Pinto había insistido siempre que la región podía beneficiarse con la actividad extractiva, los mineros acataron las resoluciones adoptadas por la intendencia para regular las labores en Arqueros ${ }^{50}$.

Por otro lado, en septiembre de 1825 se estableció en La Serena la Chilean Mining Association, cuyo gerente era el alsaciano Carlos Lambert. Su objetivo era entrar "en la habilitación de minas, comprar minas u otras propiedades cuando sea posible, y aprovechar la fuerza laboral ya existente" en Coquimbo ${ }^{51}$. Es muy probable que el intendente viera con buenos ojos las intenciones de Lambert, ya que rápidamente entró en contacto con él. Pinto sabía que esta era la oportunidad de hacer progresar la actividad económica de la región, además de una inmejorable ocasión de demostrar empíricamente sus propuestas.

En menos de un mes, la presencia de Lambert produjo resultados positivos para el país entero. Gracias a que en el último tiempo las disputas entre el centro y la periferia habían disminuido, el gobierno volvió a preocuparse de los contingentes realistas que todavía ocupaban Chiloé. Su esperanza era expulsarlos definitivamente en el verano de 1826, para lo cual era necesario contar con recursos importantes. Al enterarse de los planes de Freire, Pinto promovió un proyecto para conseguir fondos en la provincia, con la idea de que este fuera aceptado por los políticos de la capital y visto como un gesto de unidad. El plan comenzó a concretarse a principios de octubre, cuando Pinto y José Miguel Solar, presidente de la Asam-

47 Véase A.N.I.C., vol. 10, ff. 56-57.

48 El artículo 22 del primer Código minero nacional, de 1874, también prohibió a los intendentes "adquirir minas o tener parte o interés en ellas", dentro de su jurisdicción. La norma ha sido reiterada invariablemente por los Códigos posteriores. Agradezco a mi padre, experto en derecho de minas, la clarificación de algunos detalles en esta materia.

49 Véase, por ejemplo, A.N.I.C., vol. 17, ff. 515-516.

50 Véase A.N.I.C., vol. 10, ff. 56-57.

51 Simon Collier, "El Diario de Carlos Lambert, 1825-1830" en RChHG, 161, 1994-95, 301. 
blea, firmaron con Lambert un empréstito de 120 mil pesos para cooperar a la expedición libertadora de la isla.

El contrato tenía nueve artículos, pero solo dos son relevantes. El cuarto señalaba que el gobierno se comprometía a solicitar a la Asamblea "la libre i franca esportacion de pastas de plata en los puertos habilitados de la provincia, pagando los esportadores cuatro reales en marco", que ingresarían a las arcas de la provincia misma. De ese modo, Lambert podría remesar al exterior la plata de Arqueros, y de esos ingresos la región entera se vería beneficiada ${ }^{52}$. El noveno, en tanto, acordaba que en caso de que no se consiguiera la amortización de la deuda con Lambert en el término de un año y medio, "se obliga el gobierno al remate de los bienes de regulares" para conseguir el dinero ${ }^{53}$.

La negociación se llevó a cabo exclusivamente en Coquimbo. El gobierno fue representado por Pinto, aunque en Santiago se enteraron días después del contrato que unilateralmente se había preparado en la provincia. A nuestro entender existen dos razones que explican la actitud de Coquimbo: por un lado, el interés en promover las actividades mineras de Lambert en la zona y, a cambio de ello, obtener un empréstito para recuperar Chiloé; y por otro, usar esta circunstancia para reiniciar las conversaciones políticas con los santiaguinos en pos de concretar el tan anhelado proyecto nacional.

Pero las cosas no eran tan simples. El 12 de octubre, el Director Supremo había nombrado un consejo consultivo ${ }^{54}$, al cual entregó el conocimiento del acuerdo entre Coquimbo y Lambert. El 18 de ese mes, se analizó el negocio, sobre todo la cláusula que hipotecaba "al pago i amortizacion de dicho empréstito los bienes nacionales que pertenecieron a regulares, como igualmente por ser un artículo de la contrata el permiso de la libre esportacion de pastas de plata" ${ }^{55}$. Un día después, el Consejo presentó su informe sobre la materia:

Despues de largas i detenidas observaciones, que se hicieron por todos los señores del Consejo, sobre los inconvenientes que este negocio presentaba para su resolucion, ya se le concediese o negase la sancion por el supremo gobierno, porque si se negaba podria frustrarse la interesante espedicion a Chiloé, no contándose ya con el auxilio de la

52 A esas alturas, los réditos de Arqueros comenzaban a sobrepasar las fronteras de Coquimbo, hasta el punto que incluso la administración central deseaba tener algún tipo de participación en ellos. Esto quedó de manifiesto el 12 de septiembre de 1825, fecha en que el gobierno pidió a Pinto que algunos trozos de plata fueran enviados a Santiago con el fin de regalárselos posteriormente al rey de Inglaterra. Dice: "Su Excelencia el Supremo Director se halla empeñado en obsequiar al Rey de Inglaterra á nombre de la Nacion con alguna de las producciones del pais, que por su rareza ó preciosidad pueda aumentar la riqueza del Gabinete de Historia Natural de aquel Monarca. Entre otras cosas ha llamando principalmente la atencion del Gobierno la excelencia de los metales de plata que recientemente se han descubierto en esa Provincia, y cree que no solo seria un obsequio muy grato á S.M.B. un trozo de metal delo mas rico que pueda encontrarse, sino que tambien aumentaria el concepto que tiene Chile en Inglaterra por sus producciones naturales. Al efecto, S.E. me ordena encargar á V.S., como tengo el honor de hacerlo, que solicite á cualquiera costa un pedazo de este mineral", en A.N.I.C., vol. 13, sin foja exacta.

53 En Benjamín Vicuña Mackenna, El Libro del Cobre i del Carbón de Piedra en Chile, Imprenta Cervantes,, Santiago, 1883, 167-168.

54 Véase Barros Arana [1], tomo XIV, 408.

55 En Benjamín Vicuña Mackenna [76], 168. 
cantidad de este empréstito, i lo que era aun más grave, el resentimiento que podria tomar la Asamblea i provincia de Coquimbo por la repulsa de un negocio en el que creia haber hecho el más heroico servicio, retardaría i haria más difícil la reconciliacion de aquella provincia, i su avenimiento a nuestra unidad nacional, etc., etc.; i considerando tambien por el otro estremo que si se accedia a su pretension podia ser esto de un pésimo ejemplo en cuanto podia servirle de un apoyo o aliento a que las provincias o sus representaciones o gobiernos se atribuyesen prerrogativas nacionales, como imponer derechos nuevos o variar los establecidos ${ }^{56}$.

Por lo visto, el gobierno se encontraba en una posición bastante incómoda. Si desaprobaba el contrato, la expedición a Chiloé podía verse abortada por falta de fondos y los problemas con Coquimbo se agravarían, toda vez que sus esfuerzos por hacer un "bien" a la patria serían desautorizados por la capital. Pero, por otra parte, su aceptación podía ser un aliciente para que otras regiones del país comenzaran a negociar directamente con quienes creyeran conveniente y, de ese modo, arrogarse prerrogativas que competían solamente a la dirección suprema.

Aun así, la necesidad de contar con el dinero ofrecido por Lambert prevaleció. El 20 de octubre, Freire escribió a los asambleístas que había resuelto aceptar el contrato con Lambert, pero no sin antes dejar en claro que los artículos que "envolvian la atribucion que esa honorable Asamblea [de Coquimbo] se había hecho de disponer de derechos [por exportación] puramente nacionales". Por ello, llamaba a los coquimbanos a no repetir "otro ejemplar de esta clase" y a empeñarse "en remediar, si es posible, el mal ejemplo que con este paso se ha dado"57. Aunque desconocemos qué pensaron los miembros de la Asamblea de esta recomendación, es muy probable que no les haya incomodado y que concluyeran que el balance de la negociación con Lambert había sido más positivo que negativo.

Algo parecido debe haber pensado Pinto. Es evidente que sus ideas están detrás del acuerdo y el trasfondo del mismo responde a lo que siempre había deseado para la provincia. Pero también el contrato muestra que los esfuerzos de la intendencia por mantener a la región unida a la administración central rendían sus primeros frutos. En efecto, que los coquimbanos sintieran como propia la lucha en Chiloé es un triunfo de Pinto, aparte de un signo de que las cosas entre la capital y la provincia comenzaban a coincidir.

Freire se hizo a la vela con rumbo a Chiloé el 13 de noviembre de 1825 . Un día antes, delegó el mando en un Consejo Directorial compuesto por José Miguel Infante y los ministros Joaquín Campino, Manuel José Gandarillas y José María Novoa. Estos tendrían la misión de preparar el ambiente para que, a la vuelta de Freire, se convocara un nuevo Congreso Nacional. Para ello, el Director Supremo los instaba especialmente a hacer "la división del territorio dela República, que la experiencia me ha hecho conocer como el paso preliminar mas indispensable para el logro y buenos resultados de aquel [ el Congreso]"58. Coquimbo recibió esta

\footnotetext{
56 En ibidem, 168-169.

57 En ibidem, 170-171.

58 Este decreto se puede encontrar en A.N.I.C., vol. 13, sin foja exacta.
} 
noticia algunos días después, y en su respuesta, Pinto aseguró que el nombramiento del Consejo "há sido recivido enla provincia con todas las demostraciones de una aseptacion publica por la alta opinion que le meresen los individuos que la componen, de cuyos talentos, amor patrio, y consagracion por el bien publico tienen estos pueblos irrefragables testimonios" 59 .

En los pocos meses que el Consejo Directorial dirigiría los destinos del país, se consumaron las pretensiones políticas de Infante. Entre noviembre de 1825 y marzo de 1826, las ideas federalistas entrarían por primera vez en escena de una forma más o menos institucional. El 31 de enero el gobierno decretó la división provisoria de la república en ocho provincias, disponiendo que "todo lo urgente relativo a la organización y administración de las nuevas provincias se determinaría por el gobierno provisoriamente hasta la reunión de la primera legislatura nacional" 60 .

En 1826, el aura del federalismo llegaría a todo el territorio nacional, incluido Coquimbo. Para Pinto, esta no debió ser una buena noticia. Respetuoso de las diferencias y potencialidades de cada provincia, sobre todo de las de Coquimbo, Pinto sabía que había que promoverlas y hacerlas progresar, pero jamás a costa de la unidad de la nación. Pese a esto, también intuía que los vientos de la política no estaban soplando a su favor y que, por el momento, debía esperar el transcurso de los acontecimientos. Así, pues, no debe extrañar que durante gran parte del año 1826, Pinto renunciara una y otra vez a su cargo de intendente, acusando problemas de salud ${ }^{61}$. Su alejamiento se concretó, finalmente, el 29 de septiembre, al ser sustituido por José María Benavente ${ }^{62}$.

\section{VICEPRESIDENTE DE LA REPÚBLICA}

Luego de que Freire regresara de Chiloé y reasumiera el poder, en marzo de 1826 , los esfuerzos por consolidar institucionalmente el régimen republicano volvieron a manifestarse. Rápidamente se llamó a elecciones para formar un Congreso Nacional, cuyas sesiones comenzaron el 4 de julio, y se reanudaron las conversaciones para redactar una Constitución que reemplazara definitivamente la de 1823 . Los problemas surgieron otra vez cuando el Director Supremo señaló en el discurso de apertura que no estaba dispuesto a seguir en el mando, obligando a los congresales a elegir un nuevo jefe de Estado. El puesto recayó en Manuel Blanco Encalada, quien, por resolución del Congreso, se convirtió en el primer Presidente de la República ${ }^{63}$.

59 A.N.I.C., vol. 17, f. 514

60 Citado en Barros Arana [1], tomo XIV, 419. Las ocho provincias eran: Coquimbo, Aconcagua, Santiago, Colchagua, Maule, Concepción, Valdivia y Chiloé.

61 En cartas de 20 de enero de 1826 (A.N.I.C., vol. 17. ff. 517-517v), 21 de marzo de 1826 (ibidem, f. 522) y 21 de abril de 1826 (ibidem, ff. 529-529), Pinto presenta su renuncia a la intendencia de Coquimbo por motivos de salud.

62 Véase A.N.I.C., vol. 43, última foja.

63 Véase Barros Arana [1], tomo XV, 27-29. 
La elección de Blanco Encalada se transformaría en un triunfo para los congresistas que se autoproclamaban federalistas, pues, en los pocos meses que aquel estaría al mando del país, no sería capaz de oponer resistencia a casi ninguna de sus aspiraciones. El 11 de julio, el Congreso expidió la siguiente ley: "La República de Chile se constituye por el sistema federal, cuya constitución se presentará a los pueblos para su aceptación"64. Entre agosto y septiembre, la influencia del Congreso aumentó considerablemente. Blanco Encalada, en cambio, vio con impotencia cómo los proyectos del gobierno perdían terreno ante las constantes arremetidas del Poder Legislativo. Así las cosas, al Presidente no le quedó más que renunciar al cargo, con la aceptación del Congreso el 9 de septiembre de 1826. En su reemplazo, asumió Agustín Eyzaguirre, que hasta ese momento había actuado como Vicepresidente ${ }^{65}$.

En los meses siguientes, se mantuvo en vigencia la ley federal del 11 de julio, a pesar de que no contaba con una base constitucional que la legitimara. Para remediar esto, el 19 de enero de 1827 Infante presentó un proyecto de Constitución. En cincuenta artículos, esta establecía la casi absoluta independencia de las provincias, las cuales únicamente tendrían que rendir cuentas a un Congreso formado por ocho senadores, representante cada uno de ellos de las regiones que conformaban el Estado chileno ${ }^{66}$.

Aunque Eyzaguirre intentó detener el federalismo, sus esfuerzos fueron en vano. La crisis se agudizó el 24 de enero de 1827, cuando el coronel Enrique Campino sublevó a la guarnición de Santiago en contra del gobierno y del Congreso Nacional. Al enterarse que la mayoría de los vecinos de Santiago habían rechazado la insurrección, Campino ingresó a caballo al edificio que albergaba las sesiones legislativas. Desde esa posición, instó a los congresales a que se disolvieran, para cuyo efecto ordenó que sus hombres desalojaran el lugar. Solo Diego José Benavente y el diputado José Manuel Benavides se mantuvieron en sus asientos ${ }^{67}$.

Después de unas horas, los diputados acordaron "llamar al capitán general don Ramón Freire para encomendarle la salvación de la República"68, quien, luego de pensarlo y criticar los últimos acontecimientos, aceptó el encargo. El 26 de enero, Freire ya se encontraba en la provincia de Aconcagua pidiendo armas y contingentes "para formar una división con que acudir prontamente al restablecimiento del orden público"69. Campino, mientras tanto, alarmado con la noticia de que Freire estaba a la cabeza de la resistencia, solicitó el compromiso formal y explícito de los jefes y oficiales que habían participado de la sublevación. Para ello, redactó una declaración señalando las motivaciones que habían guiado al movimiento. Según él, "su primer objeto para tomar las armas y conmoverse había sido por la crisis actual en que la República se hallaba rodeada de tantos peligros", y con el

\footnotetext{
64 Citado en Ibidem, 32.

65 Véase ibidem, 51-53.

66 Véase ibidem, 94-95.

67 Véase ibidem, 98-101.

68 Ibidem, 101.

69 Ibidem, 104.
} 
fin "de que fuera electo Presidente el General don Francisco Antonio Pinto, y Vicepresidente el coronel Campino, únicas personas que en tan críticas circunstancias merecían la confianza pública y de las tropas"70.

¿Se había involucrado Pinto en estos hechos? ¿Se había enterado de cuánto acontecía en la capital? ¿Cuán ciertas eran las promesas de Campino? No hemos encontrado ningún documento que acredite la participación de Pinto en la planificación o en la consumación del motín. Por esta razón, tendemos a pensar que Barros Arana no se equivoca cuando señala que en ese momento Pinto se hallaba en La Serena, absolutamente extraño a los hechos que se desarrollaban en Santiago, y que por lo tanto, era "evidente que lo que se pretendía era entregar de inmediato a Campino el mando supremo del Estado"71. Es decir, desde un comienzo el movimiento habría tenido una connotación personalista.

Campino no fue capaz de superar la popularidad de Freire, y este reinstaló el orden el 30 de enero, siendo nuevamente proclamado -en contra de su voluntadcomo jefe de gobierno (Eyzaguirre se había retirado a su hacienda de Tango) ${ }^{72}$. La designación de Freire fue confirmada por el Congreso el 13 de febrero de 1827, en cuya ocasión cuarenta y ocho diputados se presentaron a votar para los cargos de Presidente y Vicepresidente de la República. Freire obtuvo treinta y siete votos para el primero; y Pinto veintisiete para el segundo. La elección de este último fue un triunfo de los liberales moderados, ya que intuyeron que, tarde o temprano, Freire renunciaría al cargo, dando paso a que uno de los suyos por fin condujera los destinos del país.

La prensa de la época se mostró a favor de estos nombramientos. Así, por ejemplo, El Verdadero Liberal se alegró de que por fin hubiera un gobierno estable, capaz de sepultar "la anarquia y los desordenes":

Tenemos por fin un gobierno: ha salido electo Presidente de la República, S.E. el Capitan General Freyre con 37 votos, y el General Pinto Vice-Presidente. La Patria está salvada: los ciudadanos honrados han cobrado ánimo: el triunfo de los revolucionarios no ha sido mas que de un momento, ya hemos sepultado la anarquia y los desordenes: Hemos vuelto á ver patria: ya para nosotros no habrán sino días felices, VIVA LA PATRIA, VIVA LA REPUBLICA CONSTITUCIONAL DE CHILE, VIVAN LOS GEFES EN QUIENES HEMOS PUESTO TODA NUESTRA CONFIANZA ${ }^{73}$.

El 2 de marzo de 1827, El Indicador informó que el nuevo Vicepresidente había partido desde Coquimbo, probando "en nuestro concepto que ha admitido el cargo que tan acertadamente se le ha confiado por la nacion: quiera la fortuna acompañarle, y no abandonarle jamas"74. Aunque todavía restaban dos meses para que asumiera en propiedad, el anuncio de este periódico es sintomático de lo que pensaba de Pinto la ciudadanía. Durante el mes de marzo, los redactores de $E l$

\footnotetext{
70 Citado en idem.

Idem.

Véase ibidem, 103-107.

El Verdadero Liberal, número 10, Santiago 13 de febrero de 1827, f. 50.

El Indicador, número 2, Santiago 2 marzo de 1827, f. 28.
} 
Indicador recalcaron los "grandes talentos, esperiencia y profundo saber" de Pinto $^{75}$, vanagloriándose de tener ideas parecidas a las suyas.

Ahora bien, ¿bastaba la buena fama de Pinto para que las odiosidades se detuvieran y para que Chile se enrielara definitivamente en la senda del orden administrativo? No, en ningún caso. En esos momentos, la capital estaba sumida en la más profunda división institucional, entre los que aprobaban el régimen federal y quienes consideraban que su instauración llevaría el país al colapso. En gran parte debido a esta polarización de la ciudadanía, pero también por razones personales, Freire no deseaba continuar a la cabeza de la administración, y hacía esfuerzos por retirarse cada vez que la oportunidad se le presentaba. Así, aprovechando que Pinto había arribado a Santiago unos días antes, el 2 de mayo Freire escribió al Congreso para comunicar su renuncia definitiva. Los congresales aceptaron esta determinación, y el 5 de ese mes se acordó llamar a Pinto al ejercicio de la primera magistratura ${ }^{76}$.

Pinto se dirigió al Congreso el 7 de mayo, informándole que el estado desastroso de la administración le impedía asumir tamaña responsabilidad. En los pocos días que llevaba en la capital se había hecho una idea acabada de las divisiones políticas en que habían caído sus compatriotas. Angustiado y hastiado con la situación, pedía que se le excusara del cargo:

Me hallaba en Coquimbo, cuando tuve aviso del alto honor con que me había distinguido el congreso nacional nombrándome vicepresidente de la República. Colocado a gran distancia del centro de los negocios, y llamado urgentemente por el presidente de la República, diferí mi resolución hasta ver por mí mismo el estado de nuestras cosas. Confieso ingenuamente que me he espantado; y midiendo la escala de las dificultades que circundan al gobierno con la extensión de mis fuerzas, me he convencido de que no soy hombre llamado por las circunstancias a presidir la República. Sin garantías para el gobierno, sin leyes ni reglas establecidas para gobernar, y con los demás obstáculos que el congreso no ignora, ¿cómo es posible que ose aceptar un cargo que el general Freire, con sus virtudes, con su popularidad y con su crédito militar, ha dimitido por los motivos que se expone en su abdicación? ¿Qué puedo esperar si él no ha podido dar vitalidad a la administración? ${ }^{77}$.

Como era de esperar, el Congreso se negó a aceptar su negativa, por lo que, al día siguiente, se vio en la obligación de asumir el mando del país. Aunque en teoría seguía siendo Vicepresidente, en la práctica tenía las mismas facultades y deberes que el Presidente. El Ministerio del Interior lo confió a José Miguel Solar, antiguo presidente de la Asamblea provincial de Coquimbo, el de Hacienda a Ventura Blanco Encalada, hermano del ex Presidente, y el de Guerra y Marina al general José Manuel Borgoño. Con estos nombramientos, Pinto intentó dar una señal de confianza a tres grupos: a las provincias, a los liberales moderados y a los

\footnotetext{
75 El Indicador, número 7, Santiago 17 de marzo de 1827, ff. 34-35.

76 Véase Barros Arana [1], tomo XV, 114-115.

77 Citado en ibidem, 115.
} 
militares. De esa forma, creía, el gobierno tendría mayor estabilidad y las luchas de poder se rendirían ante el espíritu de negociación ${ }^{78}$.

$\mathrm{Su}$ relación con el Congreso también estuvo inspirada en esta premisa. En tono conciliador, se dirigió a sus miembros el 8 de mayo para pedirles su colaboración:

SEÑORES. Al investirme de esta banda creo haber contraído obligaciones de inmensa trascendencia. Conozco el peso del mando; y solamente podré soportarlo, contando (como desde ahora cuento) con la asistencia de vuestros consejos, para poder satisfacer á las demandas de los pueblos. -Desde que estos han dejado de ocuparse en la guerra de la independencia, han vuelto toda su atencion á considerar los medios de asegurar su ecsistencia social: de aqui esa inquietud mal interpretada por algunos, y que sometida á un examen riguroso, no proviene de otra cosa que de la falta de leyes, o del contraste que forman las que ya se han dado con las leyes coloniales-. En vuestras manos, señores, ecsiste su destino, y la República y el Gobierno lo espera todo de la sabiduría y pureza del Congreso ${ }^{79}$.

Respetando las atribuciones del Congreso, Pinto podría contar con sus miembros y comenzar a dictar las leyes que fueran necesarias para consolidar el régimen representativo. Es cierto que algunas de ellas ya habían entrado en vigencia, pero ¿eran suficientes?, ¿cuántas de ellas "contrastaban” con las heredadas del mundo colonial? Al hacer un análisis crítico de la situación del país, Pinto estaba implícitamente mostrándose contrario al sistema federal, ya que sus logros eran discutibles y, más bien, habían confundido a muchos chilenos que estaban acostumbrados a obedecer a un poder central. Esta era la oportunidad, entonces, de preparar una Constitución centralista, sólida y perdurable en el tiempo, apoyada tanto por el Ejecutivo como por el Poder Legislativo.

Sin embargo, antes de que esto se llevara a cabo, el Congreso sufriría un nuevo traspié. Entre mayo y junio de 1827, los diputados adversarios del federalismo volvieron a discutir qué tipo de administración era la más adecuada. En nombre de ellos, Diego José Benavente señaló que las bases del federalismo no interpretaban a la opinión nacional, y que las provincias, a quienes se quería favorecer, comenzaban a condenar el sistema. Por esta razón, pedía que se consultara nuevamente a los habitantes del país acerca del régimen que deseaban, lo que obligaba, según Benavente, a disolver el Congreso y aceptar que los políticos habían fallado una vez más ${ }^{80}$.

Sus ideas fueron tomadas en cuenta, y el 19 de junio se volvió a cerrar el Congreso. La clausura del Poder Legislativo importaría en el hecho la desaparición del federalismo, lo que se confirmó el 22 de ese mes, cuando el gobierno sancionó

78 Ibidem, 115-116. Cabe señalar que Solar renunció a su cargo cuando se trasladó, desde Coquimbo, a Santiago, y que Pinto nombró como su sucesor a Santiago Antonio Pérez. Sin embargo, su pertenencia a una de las comisiones nacionales de aquella época, le impidió ejercer su cargo, obligando al subsecretario del interior, Melchor José Ramos a ejercer el ministerio. Este fue reemplazado en diciembre de 1827 por Carlos Rodríguez. Véase Ibidem, nota al pie 134.

79 Citado en La Cola del Cometa, número 9, Santiago 10 de mayo de 1827, ff. 33-34.

80 Véase Barros Arana [1], tomo XV, 116. 
una ley cuyo primer artículo disponía que se consultase "a las provincias por medio de sus asambleas la forma de gobierno por que debía constituirse la República". Los cabildos de cada departamento tendrían la obligación de "oír de palabra o por escrito a los ciudadanos que quisieran dar su opinión”, con la condición de "que no fuese por medio de reuniones populares, o de cualquiera otro modo tumultuario" $"$. En ausencia del Congreso, funcionaría una Comisión Nacional compuesta de ocho individuos designados por aquel, a razón de uno por cada provincia, que tendría como encargo elaborar en tres meses un proyecto de Constitución. El 12 de febrero de 1828, en tanto, se reuniría un nuevo Congreso para estudiar las propuestas de los comitentes ${ }^{82}$.

Ahora bien, las buenas intenciones no bastaban para detener la progresiva polarización de los políticos chilenos. En diciembre de 1827 se llamó a elecciones para el Congreso Constituyente ${ }^{83}$, declarándose que no podrían ser elegidos los "individuos que hayan sido procesados por enemigos de la independencia, comprendiendose en estos, los desterrados y fugados" 84 . Con esta medida, el gobierno quiso explicitar una vez más su adhesión al republicanismo, a sabiendas que existía un consenso generalizado sobre sus beneficios. Sin embargo, en cuanto a las formas que este podía tomar todavía existían diferencias notorias, incluso entre aquellos que se reconocían como miembros del mismo grupo. Los federales, por ejemplo, se aliaron a los liberales moderados, olvidando que habían sido estos quienes habían precipitado su colapso. Los pelucones, por su parte, superaron las diferencias sociales y se identificaron con el grupo estanquero, oponiéndose como podían a las decisiones del Ejecutivo ${ }^{85}$.

81 Citado en ibidem, 117.

82 Véase Idem. La comisión quedó compuesta por las siguientes personas: Manuel Matta, por Chiloé; Francisco Calderón, por Valdivia; Manuel Novoa, por Concepción; Ramón Freire, por Maule; Juan Albano, por Colchagua; Diego José Benavente, por Santiago; Santiago Antonio Pérez, por Aconcagua y José Ignacio Cienfuegos, por Coquimbo. Nótese la ausencia de Infante (que veía con espanto cómo las ideas federalistas perdían fuerza) y la presencia de por lo menos tres liberales moderados: Pérez, Freire y Cienfuegos, en ibidem. Con el paso de los días, Pinto fue intensificando su crítica al federalismo, y el 23 de julio le pidió a la Comisión Nacional que suspendiera inmediatamente todas las leyes que favorecieran aquel sistema. Este documento se encuentra en ibidem, 138.

83 El Monitor Imparcial, Santiago, número 17, Santiago diciembre 1 de 1827, f. 129, analizó la elección de esta manera: "Si aciertan los Liberales en la eleccion de diputados al Congreso, dicen ciertos zotes, sucederá lo siguiente: 1.- A los godos les arrancaran las barbas; 2.- A los pelucones los talegos; 3.- A los carrerinos se los entregará a O’Higgins; 4.- A los O’Higginistas a los Carreras. Gran proyecto para ganar, ecselente modo de minar la opinión, pero brusco y sin gracia: los Liberales por su parte dicen: Si acierta cierta gabilla, habrá lo siguiente, y esto no es patraña: 1.- Estanco ; 5 .- Nuestra deuda interior de cinco millones, se comprará con uno, y se solverá del caudal de los godos, del de los pelucones, clerigos, carrerinos, y O'Higginistas; volverá la inquisicion estanqueral, y principiaran las correrias sobre toda propiedad".

84 "Reglamento de eleccion de diputados al Congreso General Constituyente, Santiago Diciembre 4 de 1827", en Biblioteca Nacional de Chile, Biblioteca Americana José Toribio Medina, Manuscritos, rollo 294.40, f.2. (De ahora en adelante citado como B.N. B.M., SM).

85 Sobre los estanqueros, véase Ernesto de la Cruz y Guillermo Feliú Cruz, op. cit., tomo I; Simon Collier, Ideas y política de la independencia chilena..., op. cit., capítulo 8; Sergio Villalobos, Portales, una falsificación histórica, Editorial Universitaria, Santiago, 1989, 47-60; Magdalena Petit, Don Diego Portales (el hombre sin concupiscencia), Editorial Andrés Bello, Santiago, 1962; Juan Eduardo Vargas, "El pensamiento político del grupo estanquero", en Historia, número 9, Santiago, 1970, 7-35. 
La elección favoreció a los pipiolos, quienes superaron a sus contendores por cerca de tres mil votos. Según Barros Arana, esas cifras "confirmaban a primera vista el rumor público de que en la elección habían votado muchos hombres que no tenían derecho para hacerlo" 86 y que detrás de aquella maniobra se encontraba -no sin razón- el gobierno. La prensa pelucona y estanquera intentó impugnar el resultado, pero sus esfuerzos fueron en vano: el 25 de febrero de 1828, trece días después de lo presupuestado, se instaló formalmente el Congreso Constituyente ${ }^{87}$. Más de dos tercios de los diputados correspondían al grupo liberal ${ }^{88}$, cuyas ideas, como veremos, quedarían impresas en la Constitución de 1828.

\section{La Constitución Política de 1828}

El 25 de febrero de 1828, el Vicepresidente se dirigió a los constituyentes para informarles de lo que había acontecido durante los siete meses en que las sesiones parlamentarias se habían suspendido. Además, y al igual como lo hiciera en 1825 en la apertura de la Asamblea de Coquimbo, hizo un bosquejo de su programa de gobierno y señaló cuáles eran, según él, las principales necesidades de los chilenos. Claramente dividido en secciones políticas, culturales y económicas, el Mensaje comenzaba así:

El ardiente anhelo de los pueblos por obtener una Constitucion, su aberracion de doctrinas antisociales, el profundo cansancio que les han dejado las pasadas oscilaciones, y la completa union y tranquilidad de que hoy goza la República, son precursores inequívocos de que es llegada la época suspirada de los chilenos, de alcanzar una Constitucion ilustrada que le indemnice los enormes sacrificios que han hecho por la Independencia. [...] Ningún evento desgraciado ha trastornado el órden en los siete meses de vuestro receso, y si han sentido ciertas agitaciones en uno que otro pueblo, ha sido el efecto de nuestra inexperiencia en el uso de las elecciones populares. Mas, en todos ellos ha sido constantemente respetada la voz de la autoridad, y restablecida la tranquilidad interior sin violencia ni sacrificio alguno ${ }^{89}$.

Lograr el consenso y la unidad de los chilenos parecía ser la consigna del gobierno, y Pinto estaba dispuesto a luchar con todas sus fuerzas para conseguirlo. Como vimos, uno de los puntos más significativos para el gobierno era la educación pública, no solo por sus beneficios inmediatos y concretos sino porque podía transformarse en una herramienta de unidad. Pinto reconocía que se había avanzado bastante en la materia, pero insistía que la ciudadanía merecía una enseñanza de mejor calidad. Continuando con el Mensaje, señalaba que

86 Barros Arana [1], tomo XV, 155.

87 Véase ibidem, 156.

88 Véase ibidem, 155.

89 "Mensaje del Ejecutivo al Congreso Constituyente", en Biblioteca Nacional, Salón Investigadores, LCH 252, 1. (De ahora en adelante citado como B.N.S.I.). 
La instruccion pública es el objeto predilecto de los ciudadanos del Gobierno; pero en tan escaso tiempo apenas ha podido subministrarle algunas cortas mejoras en sus diferentes ramos. Ha sido necesario buscar elementos de que careciamos para poder desenvolver en toda su extension un plan de educacion primaria, capaz de elevarla del miserable estado en que yace en toda la República. [...] La educación científica reclama tambien las mejoras que la civilizacion ha introducido en nuestro siglo, asi en los métodos como en la eleccion de las ciencias. Algo se ha ganado en esta materia, y mucho en el interés que manifiestan los pueblos de fundar colegios, y dedicar su juventud al estúdio de cosas útiles. [...] El Ejecutivo con vuestra ayuda no descansará hasta dejar planteado uno en cada capital de provincia, mejorando en cuanto se pueda su sistema de enseñanza $a^{90}$.

Los planes educacionales de Pinto contenían tres aspectos. En primer lugar, conseguir que el Congreso apoyara sus proyectos, y de esa forma otorgar una participación y responsabilidad extra a los congresistas que, hasta ese momento, no se habían preocupado de la educación. Por otra parte, afianzar su relación con las provincias, pero siempre desde el centro político. De ahí su interés porque cada región contara con un colegio público, auspiciado por el Ejecutivo. Finalmente, combinar un buen sistema de enseñanza primaria con "el estudio de cosas útiles", es decir, mezclar los dos ejes de la Ilustración: el conocimiento teórico con el trabajo empírico.

Algo de esto se puede apreciar también en el análisis económico presentado por Pinto ante el Congreso. Como intendente de Coquimbo había intentado potenciar las actividades mineras, argumentando que su explotación podía repercutir directamente en la agricultura. En 1828, mantenía una idea similar, aunque sus ejemplos se concentraban en la relación entre el comercio y la actividad agrícola:

La habilitacion para el comercio de cabotaje de los nuevos puertos Colcura, Tomé, Topocalma, Vichuquen, San Antonio, Papudo, y Conchalí ha reanimado nuestra agricultura, y roto las trabas que oprimían á nuestra naciente industria. No es fácil calcular por ahora la inmensa influencia de esta medida sobre los progresos del comercio y navegacion, y el desarrollo de la riqueza de muchas provincias, habría permanecido sin ella, eternamente estacionario. [...] Trabajan comisiones nombradas por el Gobierno para mejorar los reglamentos de comercio, aduanas, y contabilidad de las oficinas fiscales; y el resultado de sus observaciones os será presentado oportunamente. Todos estos ramos piden una reforma radical; asi para desencadenar nuestra industria, como para hacer mas productivos los ingresos nacionales, y evitar las vejaciones anexas á su exáccion ${ }^{91}$.

Al cerrar su Mensaje, Pinto señaló a los congresistas que "todos los pueblos se hallan completamente unidos", cuestión que se había logrado no a través de "la coaccion ni la intriga", sino de "la mas cordial y sincera adhesion de los chilenos á componer un todo homogéneo". Les pedía que aquella unidad se mantuviera, para que "el espíritu de provincialismo que ha devorado tantos pueblos de América"92 no se expandiera por Chile.

\footnotetext{
90 Ibidem, 2 .

91 Ibidem, 3

92 Ibidem, 4.
} 
La preparación de la nueva Constitución comenzó en los primeros días de marzo. Recordemos que el 22 de junio de 1827 se había encargado a la Comisión Nacional que redactara un proyecto constitucional, pero que por las más variadas razones sus miembros no habían avanzado mayormente. El Congreso de 1828 eligió una nueva Comisión, compuesta por siete individuos, cuya misión era ejecutar este trabajo en el plazo perentorio de sesenta días. La primera y más importante discusión giró en torno a qué tipo de régimen era el más adecuado para los chilenos: el federal o el unitario. Después de acaloradas sesiones, se optó por combinar ambas posturas ${ }^{93}$, aunque con el tiempo los unitarios irían ganando preponderancia.

La Comisión presentó al cabo de tres semanas un borrador del proyecto, y su perfeccionamiento se encargó al literato español José Joaquín de Mora, llegado a Chile a principios de febrero de ese año. Mora se había desempeñado como consejero de Bernardino Rivadavia en Buenos Aires, hasta que la caída de este lo obligó a buscar asilo en Chile ${ }^{94}$. Al enterarse, Pinto no dudó en contratar sus servicios, a sabiendas que su acabada preparación intelectual sería de suma ayuda para continuar con el proceso modernizador de la nación. El texto revisado del proyecto (que entonces constaba de 128 artículos) fue impreso y mostrado a los diputados el 2 de junio en Valparaíso ${ }^{95}$.

Los diputados estudiaron la propuesta de Mora durante todo el mes de junio, aprobándose sesenta artículos sin mayores problemas ni dilaciones. Empero, cuando la labor del Congreso parecía consolidarse, nuevas revueltas vendrían a debilitar la poca estabilidad política que se había conseguido durante el mandato de Pinto. El 4 de julio, los congresistas se enteraron de que el oficial Pedro Urriola, a la cabeza del batallón número 6 (Maipo), se había alzado en armas en San Fernando la noche del 28 de junio, asumiendo la intendencia de la provincia de Colchagua al día siguiente. Pretendiendo dar una connotación federalista al movimiento, los alzados reclamaron que las disposiciones del gobierno central no respetaban las demandas provinciales. Pinto intentó bajar el perfil de la situación, ofreciendo un indulto general a los sublevados en caso que abandonasen las armas.

93 Véase Barros Arana [1], tomo XV, 162. El 24 de enero de 1828, El Monitor Imparcial, número 22, Santiago, f. 141v, llamó a los chilenos a dejar las divisiones odiosas entre federalistas y unitarios: “¿Si volveran nuestros oidos a percibir las voces, sistema unitario, sistema federal que son la manzana de la discordia, y la piedra angular de inacabables cuestiones de puro nombre? Ojala desprendiendonos de caprichos y ecsaltaciones que solo sirven a escandecer los animos de los que marchan tras el sonido de la voz, sostituyéramos la de SISTEMA POPULAR REPRESENTATIVO que se repitiese mil veces por cada ciudadano todos los dias, y que el planteamiento de este, fuese sobre la base de una perfecta igualdad entre las provincias y pueblos y el uso libre de sus derechos municipales, es decir, el de promover y atender a los ramos de su felicidad é intervenir en el nombramiento de sus mandatarios".

94 Sobre el gobierno de Rivadavia y su caída, véase Carlos S. A. Segreti, Bernardino Rivadavia, Hombre de Buenos Aires, ciudadano argentino, Editorial Planeta, Buenos Aires, 2000, 337-41; Klaus Gallo, "Jeremy Bentham y la 'Felíz Experiencia': Presencia del Utilitarismo en Buenos Aires 18211824”, en Prismas. Revista de Historia Intelectual, Número 6, 2002, 79-96 y Klaus Gallo, “Una sociedad volteriana? Política, Religión y Teatro en Buenos Aires 1821-1827”, en Revista Entrepasados, N.27, 2005

95 Véase Barros Arana [1], tomo XV, 179. 
Pero al ver que la intransigencia de los amotinados era más fuerte que su espíritu de negociación, el Ejecutivo se vio en la obligación de enviar a Colchagua al Ministro de Guerra, general Borgoño, a la cabeza del batallón número 7 (Concepción), con el fin de forzar un acuerdo con Urriola. El 16 de julio, el gobierno se enteró de que las tropas de Urriola, acompañadas del regimiento de dragones de Curicó, avanzaban sin mayor dificultad hacia Santiago, hasta el punto que la propia integridad del Vicepresidente parecía en peligro. Pinto reunió a todas las fuerzas que se hallaban en la capital, que sumaban escasamente cuatrocientos soldados mal instruidos, y se puso en marcha hacia la chacra de Ochagavía, para cerrar el paso a los insurgentes. Sin embargo, al ser superado el día 18, él y sus hombres hubieron de regresar a la capital ${ }^{96}$.

Al día siguiente, Urriola se comunicó con la Asamblea provincial de Santiago y nombró como sus apoderados a José Miguel Infante, José María Guzmán, Nicolás Pradel y Manuel Magallanes, quienes se comprometieron a reunirse con él para discutir las demandas principales del alzamiento. En esa ocasión, Infante y Pradel manifestaron que la "situación no podía solucionarse sino con la separación del general Pinto" de la vicepresidencia, "con la disolución del Congreso y con la convocación de otro que viniera a constituir al país sobre bases más conformes a la voluntad nacional" 97 .

Los habitantes de Santiago repudiaron la actitud de Infante y brindaron todo su apoyo al gobierno. Urriola, en tanto, intentó que Diego José Benavente abogara para retirar de su cargo a Pinto, pero aquel les "contestó que no podia admitir semejante encargo, por que aunque lo hicieran pedasos no reconocia en ellos ninguna autoridad" 98 . Gracias a ello, el poder del Vicepresidente no fue mayormente cuestionado, y el motín fue perdiendo vigor. A las once de la noche del día 20, Pinto había tomado completamente el control de la situación, y así lo hacía saber a los congresistas, que se encontraban en Valparaíso:

Ecsasperados los amotinados de no encontrar apoyo en ningun hombre de honor dijeron que vendrian á la Plaza á echarse sobre mi persona, y nombrar á su arbitrio gefe de la Republica. Con esta noticia subí á la Sala del Gobierno donde estaba el Pueblo reunido y le juré no abandonarlo hasta que no me ensartasen en las bayonetas, despedi á los ciudadanos dandoles las gracias por su entusiasmo patriotico y previniendoles que á la señal de toque á fuego en la Catedral se reuniesen inmediatamente. [...] Con un Edecan mandé llamar al caudillo [Urriola] de la fuerza. Vino inmediatamente y me suplicó le diese una audiencia secreta al menos por su pronta obediencia á mi orden. Se la concedi; y habiendome dicho entre otras cosas, que no precisa por ahora poner en el conocimiento del Congreso, que habian proclamado á estilo de bando por Intendente de esta Provincia á D. José Miguel Infante y fijado carteles al mismo objeto en las esquinas, mandé a presencia del Pueblo que se arrancasen y quemasen en la plaza, pero no se encontró ninguno porque ya los ciudadanos los habian hecho pedasos. [...] Me faltan

96 Véase Ibidem, 184-185

97 Ibidem, 186.

98 "Comunicación oficial del Vice Presidente de la República al Congreso Nacional, Santiago Julio 20 de 1828, a las once de la noche", en B.N. B.M. Ms, rollo SM 286.8., f. 1 . 
espresiones para esplicar el espiritu publico que ha desplegado en estos dias el Pueblo, y solo me limitaré á decir que su entusiasmo ha sido superior á cuantos nos recuerda la historia de los mejores tiempos de Roma ${ }^{99}$.

Las repercusiones del alzamiento de Urriola no se hicieron esperar. Pinto fue ratificado en su puesto y a las tropas del Maipo y de los dragones de Curicó se les concedió un indulto general, otorgado expresamente por Pinto ${ }^{100}$. Entre estos, se encontraban el propio Urriola y los vecinos de San Fernando que le habían dado su apoyo. El Congreso aceptó el indulto dado por Pinto, entre otras cosas porque respetaba y agradecía su actuación en la terminación de la revuelta ${ }^{101}$. La generosidad del Vicepresidente también fue recibida de buena forma por la ciudadanía, por más que el gobierno dejara en claro que "cualquier otro movimiento militar que pudiese ocurrir en lo sucesivo, será irremisiblemente castigado con todo el rigor de las leyes"102.

Agradecido de la oposición por haber recibido su ayuda en esta crisis, Pinto nombró en el Ministerio de Hacienda, que estaba vacante por renuncia de Blanco Encalada, a Francisco Ruiz Tagle, uno de los pelucones más acaudalados y respetados del sector conservador. Su intención era seguir buscando el máximo de adherentes posibles, mediante una política constructiva y tolerante que no dejara a nadie fuera de los negocios públicos. No obstante, también hubo algunos opositores que consideraron que los inculpados no merecían el indulto y que la actitud del gobierno había sido débil. En respuesta, Pinto expidió una proclama el 30 de julio de 1828 , en la que pedía a sus compatriotas que olvidaran las rencillas de los últimos días, y que no juzgaran antes de que los tribunales de justicia se pronunciaran sobre la culpabilidad de los instigadores, como Infante y Pradel:

Compatriotas: [...] Vuestra opinion se ha pronunciado con unanimidad y energía contra los que señalabais como verdaderos autores de los pasados disturbios. Esta acusacion pública, que se me dirigia por ciudadanos de todas clases me imponia un deber sagrado. Lo he cumplido. Los tribunales, á cuyo fallo están sometidos estos hombres sobre los cuales gravitan las sospechas de la nacion, consumarán una obra tan necesaria á su dignidad como á su reposo. Mi mas vehemente deseo es que puedan acreditar su inocencia y que no aparezca un solo chileno manchado con el torpe delito de enemistad á su patria. Pero nunca me serán indiferentes las ofensas que ha recibido la nacion. Si está probado el crímen, recaiga sobre él la severidad de la lei. Para conseguir este gran resultado no bastan vagas designaciones; se necesitan pruebas, y todo el que pueda suministrarlas está obligado á prestar al órgano de la justicia las luces que puedan guiarlo en su indagacion. No se diga jamas que el triunfo que habeis conseguido ha exitado en vosotros pasiones malévolas y rencorosas. Ya que habeis revelado el delito, demostrad su existencia. De los

99 Idem.

100 El indulto es del 22 de julio de 1828 y se encuentra en B.N. B.M. Ms, rollo SM 128.167, sin foja exacta.

101 Véase Véase Barros Arana [1], tomo XV, 191.

102 En B.N. B.M. Ms, rollo SM 128.167, sin foja exacta. 
contrario, en lugar de un servicio eminente á la patria, resultará un desaire á la autoridad que ha acojido vuestros votos ${ }^{103}$.

El Congreso era de la misma opinión que el Vicepresidente y en cada momento habían apoyado las medidas del Ejecutivo, mostrándose abiertos a seguir los consejos de Pinto en cuanto a trabajar mancomunados por el bien del país. Esto quedó de manifiesto, finalmente, el 6 de agosto cuando los cuarenta y dos diputados presentes oyeron con satisfacción la lectura general de la Constitución ${ }^{104}$. Ese mismo día, cumpliendo con el artículo final de ella, se procedió a organizar "un poder legislativo provisorio que funcionaría hasta que se hicieran las nuevas elecciones" 105 .

Pinto recibió esta noticia el 8 de agosto, y rápidamente compartió su júbilo con los habitantes de la capital:

Acabo de recibir la suspirada noticia oficial de haberse firmado la Constitucion por nuestros legisladores. Me apresuro á comunicároslo persuadido del jubilo intenso que tan feliz anuncio debe producir en vuestros corazones. El mio está lleno de la satisfaccion mas pura. COMPATRIOTAS! Ya está sancionado el pacto de nuestra union: ya cesaron nuestras oscilaciones é incertidumbres. Consolidemos con nuestra observancia esta obra de la sabiduría de nuestros representantes ${ }^{106}$.

La Constitución se promulgó ese 8 de agosto, aunque comenzó a circular al día siguiente, precedida de un Mensaje a la Nación firmado por Pinto. Es muy probable, siguiendo a Barros Arana, que las palabras del Vicepresidente hayan sido revisadas y complementadas por José Joaquín de Mora, que conocía detalladamente cada uno de los artículos ${ }^{107}$. El trasfondo jurídico que se encuentra en este discurso marca una diferencia sustancial con otras intervenciones de Pinto. Dice:

Chilenos: Ha llegado el día solemne de la consolidación de nuestra libertad. Ella no puede existir ni jamás ha existido sin leyes fundamentales. Ya las tenemos. [...] Al anunciaros la promulgación de la Constitución que habéis deseado con tanto anhelo, y de la que os han hecho dignos vuestras virtudes, no creáis que se os imponen obligaciones penosas y coartaciones violentas, indignas de la calidad de hombres libres. Las leyes que vais a recibir no son obra tan solo del poder, lo son principalmente de la razón. Cesaron para nosotros los tiempos en que la suerte nos condenaba a la ciega obediencia de una autoridad sin límites.

A continuación, se explayaba sobre las garantías que otorgaba la Constitución, que iban desde la protección a "la santa religión que profesáis", hasta "presentar vuestras reclamaciones y quejas a los diferentes órganos de la soberanía nacional”.

103 En B.N. B.M. Ms, rollo SM 348.3, f. 90. El caso de Infante fue el más difícil de solucionar, debido a que su lucha por la causa de la independencia era agradecida por casi todos los ámbitos de la sociedad. Véase Barros Arana [1], tomo XV, 192.

104 Véase ibidem, 194.

105 Ibidem, 195.

106 En B.N. B.M. Ms, rollo SM 348.3, f. 91

107 Véase Véase Barros Arana [1], tomo XV, 195. 
El único sistema político que podía garantizar este "libre uso de nuestras prerrogativas" era el representativo, ya que aseguraba "el inapreciable bien de la elección directa" y el equilibrio de los poderes del Estado.

Para Pinto, la Constitución de 1828 era la culminación brillante del proceso liberalizador que había vivido el país desde 1810. Sus artículos permitían, por ejemplo, que las provincias disfrutaran de sus derechos particulares, pero que al mismo tiempo se sintieran parte de una nación homogénea y perdurable en el tiempo. En ese sentido, Julio Heise no deja de tener razón cuando sugiere que esta Carta "interpretaba con gran acierto la realidad histórico-cultural del momento"108, más aún tomando en cuenta que el propio Mora se había encargado que la Comisión preparatoria tuviera presente "no solo las doctrinas de los escritores más ilustres y las instituciones de los pueblos más célebres, sino las circunstancias que han influido muy particularmente en sus opiniones". Para él, "las leyes más sabias llegan a ser las más funestas cuando no se acomodan a las ideas y a las costumbres de los hombres que han de practicarlas"109.

La Constitución recibió duras críticas de los pelucones, ya que la consideraron demasiado liberal para la época, y por ende, ajena a la realidad del país. A nuestro entender, los reparos de la oposición tuvieron cuatro flancos: por un lado, estimaron que su redactor adhería a un tipo de liberalismo (inspirado en la Carta española de 1812) que no respetaba las condiciones políticas en que vivía Chile; por otro, sostuvieron que el parlamento disfrutaría de un poder desmedido, incluso por sobre el Ejecutivo; en tercer lugar, no creyeron suficiente que el artículo tercero declarara que la religión del Estado era la Católica Apostólica Romana, "con exclusión del ejercicio público de cualquiera otra", pues el siguiente señalaba que nadie podía ser "perseguido ni molestado por sus opiniones privadas"; finalmente, para algunos terratenientes fue una dura derrota que la Constitución de 1828 declarara abolidos los mayorazgos.

En cuanto a lo primero, las observaciones eran más o menos ciertas, pues la base dogmática de Mora había sido, en efecto, la Ley Fundamental dictada en Cádiz en 1812. Si revisamos los artículos segundo, tercero y cuarto de la Constitución española, encontramos lo siguiente:

Art. $2^{\circ}$. La Nación española es libre e independiente, y no es ni puede ser patrimonio de ninguna familia, ni persona. Art. $3^{\circ}$. La soberanía reside esencialmente en la Nación, y por lo mismo pertenece a esta exclusivamente el derecho de establecer sus leyes fundamentales. Art. $4^{\circ}$. La Nación está obligada a conservar y proteger por leyes sabias y justas la libertad civil, la propiedad y los demás derechos legítimos de todos los individuos que la componen ${ }^{110}$.

En tanto, el artículo primero de la obra de Mora decía que "La Nación chilena [...] es libre e independiente de todo poder extranjero. [...] No puede ser el patri-

108 Julio Heise, 150 años de evolución institucional, Editorial Andrés Bello, Santiago, 1996, 37.

109 Citado en ibidem, 35.

110 En Luis Sánchez Agesta, Documentos constitucionales y textos políticos, Editora Nacional Cultura y Sociedad, Madrid, 1982, 220. 
monio de ninguna persona o familia"; el vigésimo segundo, que "El ejercicio de la soberanía, delegado por la Nación en las autoridades que ella constituye"; y el décimo, que "La Nación asegura a todo hombre, como derechos imprescriptibles e inviolables, la libertad, la seguridad, la propiedad, el derecho de petición, y la facultad de Publicar sus opiniones". Es decir, Mora seguía de cerca la columna vertebral del pensamiento liberal español.

También es efectivo que la Constitución de 1828 otorgaba una mayor autonomía al Poder Legislativo. Sin embargo, ¿significaba esto que el Presidente perdía su facultad para dirigir el país? No parece claro: el artículo 83 define las atribuciones del Ejecutivo, entre las que destacan por lo menos tres, de gran importancia a la sazón: "proveer los empleos civiles, militares y eclesiásticos"; "destituir los empleados por ineptitud, omisión o cualquiera otro delito"; y "ejercer, conforme a las leyes, las atribuciones del patronato", aunque sin presentar "obispos sino con aprobación de la Cámara de Diputados". Por otro lado, y como bien dice Heise, la Constitución de 1828, a diferencia de la que la reemplazará en 1833, no contiene las leyes periódicas que ponen freno al autoritarismo presidencial, por lo que difícilmente el Ejecutivo podía quedar subordinado por completo al parlamento ${ }^{111}$.

Por esta razón, nos atrevemos a pensar que lo que verdaderamente molestó a la oposición conservadora no fue tanto el liberalismo de Mora o la excesiva influencia del Congreso, como los preceptos que se referían a la religión y a los mayorazgos. El artículo cuarto volvió a poner en el tapete la discusión sobre la tolerancia religiosa, aunque esta vez diferenciando lo público de lo privado. Hasta entonces, el debate se había centrado en las repercusiones de dos actividades públicas realizadas por los protestantes, a saber, el entierro de sus seres queridos y la celebración de sus ritos. Ahora, se penalizaban aquellos actos, pero se daba espacio para que se practicaran privadamente, lo que, en el hecho, significaba un apoyo por lo menos tácito a la libertad de culto. La Constitución, entonces, no interfería en las conciencias sino en cómo las manifestaciones religiosas podían afectar la convivencia entre el Estado y la población civil.

Finalmente, el problema de los mayorazgos también se insertaba en la relación entre el Estado y la sociedad. Si pensamos que Mora había intentado conciliar el resguardo de la propiedad privada con la igualdad de los ciudadanos ante la ley, resulta obvio que un privilegio de esa naturaleza entorpeciera su objetivo. El artículo 125 decía que "todo hombre es igual ante la ley"; y el 126, declaraba que:

No hay clase privilegiada. Quedan abolidos para siempre los mayorazgos, y todas las vinculaciones que impidan el enajenamiento libre de los fundos. Sus actuales poseedores dispondrán de ellos libremente, excepto la tercera parte de su valor que se reserva a los inmediatos sucesores, quienes dispondrán de ella con la misma libertad.

Para Mora y Pinto, los mayorazgos eran un vestigio del régimen colonial, comparable quizás solo con las encomiendas del siglo XVII, en cuanto los mayorazgos también concentraban la tierra en muy pocas manos. En efecto, al ser el hijo mayor

111 Véase Julio Heise [145], 37. 
quien heredara la gran parte de la propiedad, el latifundio y la consiguiente desigualdad social se incrementaban. La posición de Mora respondía, en primer lugar, a un fin jurídico, que buscaba garantizar la igualdad ante la ley y reglamentar mejor el derecho de sucesión. Para que esto no chocara con la propiedad privada, el Estado únicamente regularía que las herencias fueran repartidas equitativamente, sin involucrarse en las decisiones que tomaran los herederos con respecto a su dinero.

Pero Mora también tuvo una razón práctica cuando planteó su propuesta sobre los mayorazgos. Siguiendo los principios del liberalismo económico, el español pensó que su abolición aumentaría el número de propietarios, "cuya primera consecuencia sería la concurrencia de vendedores y la baja de los precios"112. Gracias a esto, la agricultura se dinamizaría, al igual que la actividad comercial entre los distintos puntos del país. Otra vez, la teoría política y el pragmatismo económico de la Ilustración fundían sus fuerzas en el gobierno de Pinto. ¿Cuánto duraría?

Las diversas corporaciones del Estado juraron la Constitución de 1828 el 17 de septiembre ${ }^{113}$, un mes y medio después de que Pinto se dirigiera a la nación. A juzgar por los documentos oficiales ${ }^{114}$ y por la prensa de la época ${ }^{115}$, la ciudadanía recibió gustosa la obra de Mora. La oposición continuó sus ataques, pero, por el momento, sus críticas no empañaron la labor de Pinto, quien pudo disfrutar de algunos meses de paz antes de que las diferencias políticas volvieran a dividir irreconciliablemente a la sociedad chilena. Por el momento, la vicepresidencia podía respirar tranquila: de una u otra forma, sus objetivos se habían logrado.

\section{CONSIDERACIONES FINALES}

A lo largo de estas páginas se han abordado aspectos importantes de la vida pública de un personaje relevante, pero poco conocido, de los inicios del siglo XIX chileno. Como vimos, Pinto convivió con tres corrientes políticas durante la década de 1820: el federalismo, el conservadurismo y el liberalismo moderado. Para muchos, el primero era una radicalización de las posturas liberales, pues aspiraba a que las provincias tuvieran el máximo de autonomía posible. Guiados por Infante, los federalistas fueron tomando conciencia de grupo a medida que avanzaba la década, pero nunca alcanzaron a posicionarse verdaderamente, ni siquiera entre los más entusiastas representantes provinciales. Los pelucones -apoyados posteriormente por los estanqueros- lucharon durante estos años para que la revolución no

\footnotetext{
112 Citado en Ricardo Donoso [32], 133.

113 Véase Barros Arana [1], 195.

114 Véase, por ejemplo, Zenón Urrutia, "La promulgación y jura de la Constitución de 1828 en la provincia de Concepción”, en Revista Chilena de Historia y Geografía, número 137, Santiago, 1969.

115 Véase, entre otros, El Monitor Imparcial, número 28, Santiago, 14 de septiembre de 1828, f. $155 \mathrm{v}$, El Centinela, número 1, Santiago, 3 de diciembre de 1828, 1, f. 1, El Centinela, número 2, Santiago, 10 de diciembre de 1828, f. 1 .
} 
pasara por encima de los preceptos de la Iglesia. Además, en cada oportunidad que se les presentó, defendieron con ahínco sus intereses económicos, intentando no ceder a las declaraciones políticas que proponían una mayor igualdad social. Los liberales moderados, como fue el caso de Pinto, inconscientemente mezclaron ambas posturas, tanto en su relación con las regiones como con el catolicismo.

En su calidad de intendente de Coquimbo, Pinto lidió estrechamente con la relación centro-periferia. En 1825, presenció la apertura de la primera Asamblea Provincial de la región, que nació al amparo de las ideas federalistas. No obstante, los asambleístas nunca se alejaron del gobierno central, e incluso criticaron a los que prometían falsas quimeras de autonomismo. Por otro lado, Pinto jugó un papel de primera importancia en los nuevos hallazgos mineros, que dinamizaron la economía coquimbana. Con una acertada visión de futuro, planteó una serie de reformas que, de una u otra forma, servirían para generar un intercambio comercial entre los que se dedicaban a la labor extractiva y aquellos que vivían de la actividad agrícola. En este caso, la intervención del Estado permitió que las tecnologías extractivas se modernizaran, cuestión que fue recompensada a fines de ese año, cuando gracias al descubrimiento de Arqueros y a la intercesión de Pinto y de Lambert, Freire pudo culminar las guerras de independencia en Chiloé.

Su relación con la Iglesia también estuvo inspirada en este espíritu de negociación. Siguiendo los cánones del “despotismo ilustrado", Pinto luchó porque el Estado heredara de los reyes españoles el derecho de patronato, y de esa forma mantener el control de los nombramientos eclesiásticos. Esta prerrogativa era de evidente relevancia, toda vez que los sacerdotes podían convertirse, a través de la palabra o de la evangelización, en una herramienta de difusión del republicanismo. Sin embargo, al mismo tiempo hizo lo que estuvo a su alcance para que el catolicismo continuara siendo la religión del Estado, y así quedó impreso en la Constitución de 1828. En ese sentido, ni siquiera la naciente tolerancia puso en entredicho a la Iglesia, sino que únicamente abrió las puertas para que otros ciudadanos del mundo se sintieran cómodos en un país como Chile.

Todos estos pergaminos intelectuales y políticos ayudaron a que la ciudadanía reconociera en Pinto al hombre indicado para dirigir los destinos del país. Asumiendo la primera magistratura en 1827, su paso por el gobierno tuvo altos y bajos. Los motines y revueltas protagonizados por los adeptos al federalismo no alcanzaron a poner en jaque el sistema administrativo, aunque tuvieron suficiente influencia para que los chilenos reclamaran una institucionalidad más estable. Los juristas e intelectuales de la época se encargaron de cumplir esta expectativa, intentando dejar de lado las pasiones y generando los espacios necesarios para que la sociedad confiara en el sistema republicano. Pues, la verdad es que en un país como Chile, donde el tradicionalismo monárquico había imperado tan fuertemente durante siglos, no resultaba fácil que los habitantes comprendieran el significado de la revolución ni menos que la aceptaran sin hacer resistencia. De ese modo, durante el mandato de Pinto, la educación, la prensa y también la Constitución de 1828, sirvieron para difundir los principios políticos, económicos y culturales de la emancipación. 
Por esto, concordamos con Julio Heise que la década de 1820 fue un periodo de formación y aprendizaje antes que de "anarquía"116. Si pensamos que los proyectos constitucionales de la época fueron evolucionando y perfeccionándose; que la participación política fue haciéndose cada vez más activa; que el Estado logró consolidar la independencia en todo el territorio; que el liberalismo moderado se impuso sobre los radicalismos extremos; que la educación pública se perfeccionó a lo largo y ancho del país; y que la consagración constitucional de 1828 sirvió de inspiración para la Carta de 1833, parece obvio señalar que en esta época el "anarquismo" no se hizo presente. Así, pues, también es claro que la generación liberal de Pinto, incluidos muchos de los militares, adhirió sinceramente a la modernidad políticocultural de la revolución hispanoamericana ${ }^{117}$, y que su caída en los años 1829 y 1830 se debió a errores coyunturales y a aspiraciones incontroladas de sus enemigos antes que a una cuestión de fondo.

\footnotetext{
116 Véase Julio Heise [8], sobre todo la tercera parte. Sergio Villalobos [117], $72-77$ y Gabriel Salazar, Construcción de Estado en Chile (1800-1837). Democracia de los "pueblos". Militarismo ciudadano. Golpismo oligárquico, Editorial Universitaria, Santiago, 2005, también destacan que, durante la década de 1820, no hubo "anarquía", por lo menos en el caso de los liberales moderados.

117 Véase Claudio Rolle, "Los militares como agentes de la revolución”, en Ricardo Krebs y Cristián Gazmuri (editores), La Revolución Francesa y Chile, Editorial Universitaria, Santiago, 1990.
} 